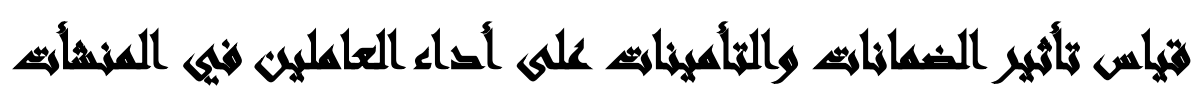

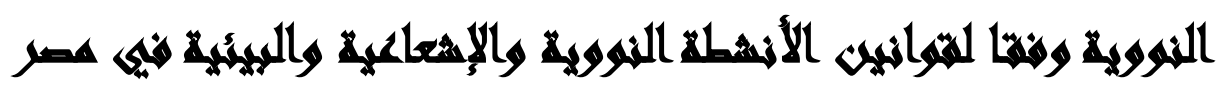

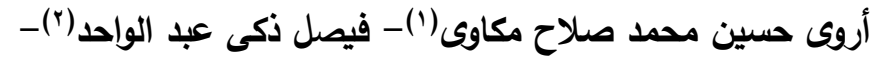

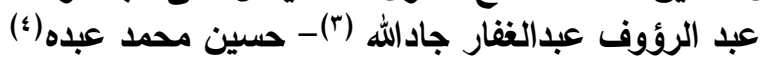

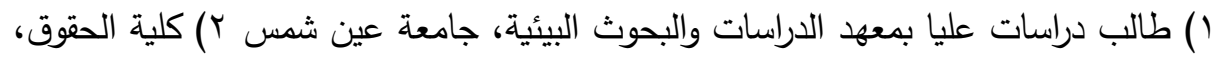

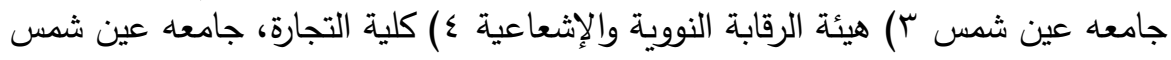

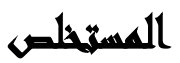

يسعي هذا البحث إلى تحقيق هدف رئيسي وهو قياس أثر الضمانات والتأمينات على والثي

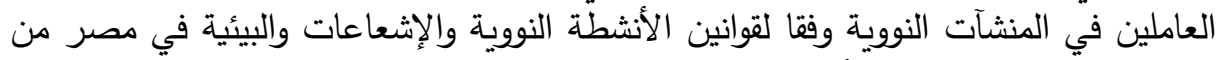

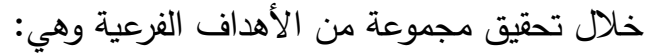

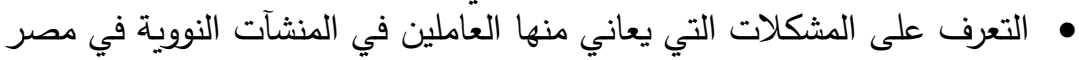

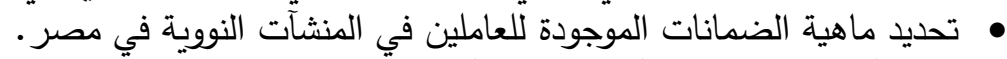

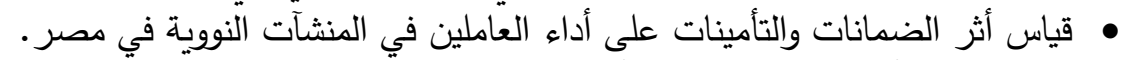

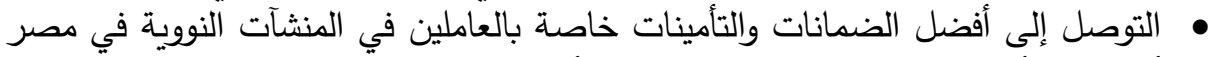
أفضل إن أمكن، وتسليط الضوه على طبي التيعة أعمال المنشآت آلنووية في مصر .

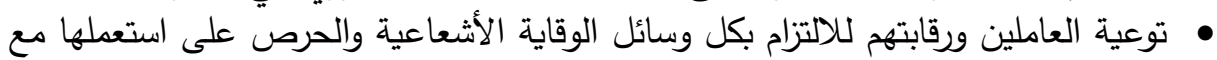

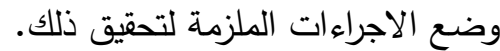

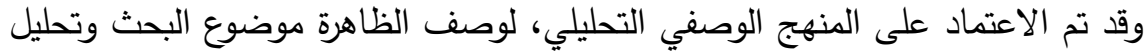

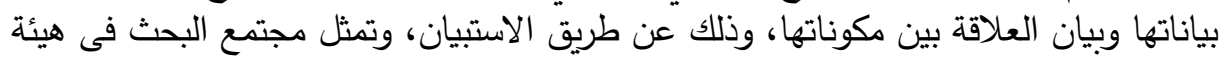

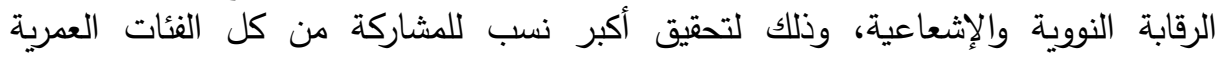

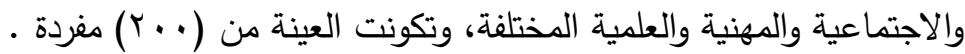
وقث توصل البحث إلى: واعنة • توجد علاقة جوهرية ذات دلالة الحصائة الائية للضمانات والتأمينات وأداء العاملين في المنشأت

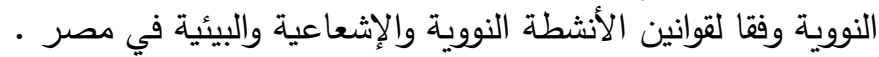
• أن الهيئات النووية أخذت بنظام الخطط المعده النظة مسبقأ لَّنع حدوث كوارث وكيفية إدارة الأزمة . الأنات

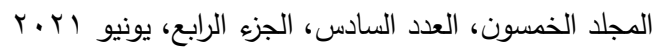

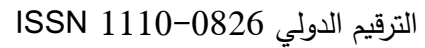


• العمل على تطوير القواعد القانونية والقوانين الخاصة بتعويض العاملين في مجال

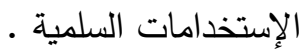

• عدم الإهتمام بالوعي المهني والقانوني بالنسبة لـهام العاملين داخل هيئة الطاقة الذرية،

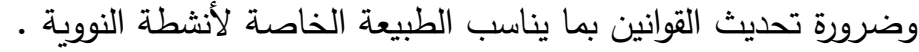
• إنخفاض المستوى المعرفي لدى العاملين بالمجال الإشعاعي مما يزيد من الأخطاء البشرية البراية

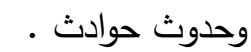
ومن أهم التوصيات : موادث : • العمل على المزيد من التوعية بالادراك البيئي وعلاقته بعملهم وتأثيره في تقليل معدلات

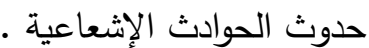

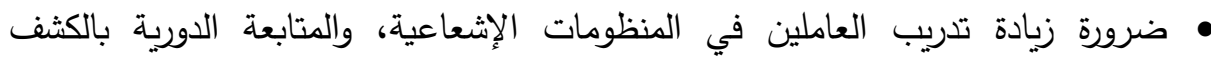

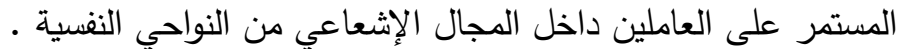

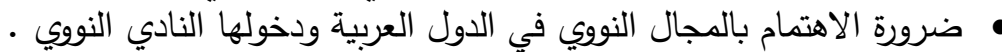

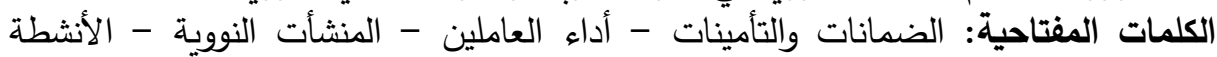
النووية والإشعاعية والبيئية

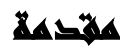

أصبحت الطاقة النووية واستخداماتها السليمة مادة جدلية تضاربت الآراء حولها بين مؤيد ومعارض، لا بل أنها أصبحت موضوع للنقاش والجدل على طاولات السياسين والاقتصاديين إضافة الى العلماء والمهندسين. لقد دخل العالم في عصر جديد للطاقة، هى الطاقة النووية التي باتت اليوم أحد أهم مصادرها، فلهذه الطاقة مظهران متتاقضان فهي إما أن تكون سبب هلاك وفناء ودمار لكل

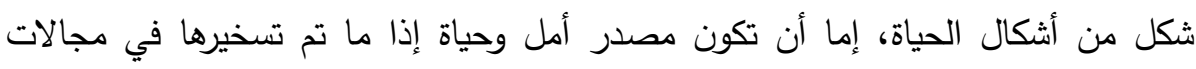
وإعمالات سليمة موجهة لرفاهية ورخاء الإنسان .من هنا يتضح لنا جليا ما مدى ازدواجية أعمال واستخدام هذه الطاقة الفتاكة من جانب والمانحة للأمل من جانب آخر ، وعليه حاولنا في هذا المدخل التمهيدي إلقاء الضوء على مجالات استخدام هذه الطاقة قبل أن تتوغل بشكل أكثر دقة في تفاصيل استخدام كل مجال وجملة التدابير والضمانات التي سعى المجتمع

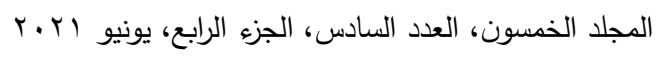

$$
\begin{aligned}
& \text { الترقيم الدولي 0826-0 }
\end{aligned}
$$


الدولي لوضعها لضمان استخدامها بشقيها دون أن يكون لها انعكاسات تمس سلامة الإنسان

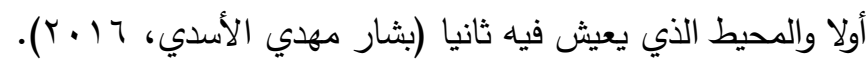

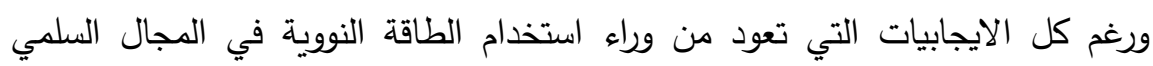
وسعي المجتمع الدولي اليوم لنشر استخدامها عبر كل دول العالم بثكل متساوي، يبقى الدارس لهاب للعلوم النووية والمتخصصون يدركون تماما أن امتلاك الطاقة النووية حتى وإن كان موجه

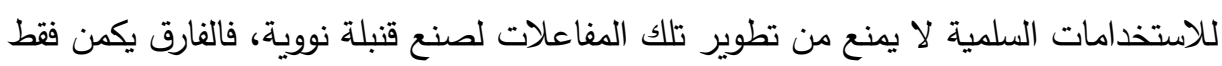

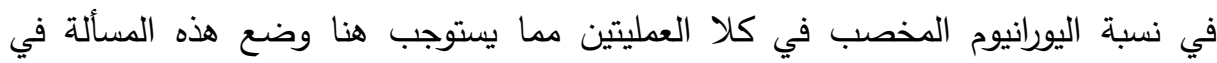

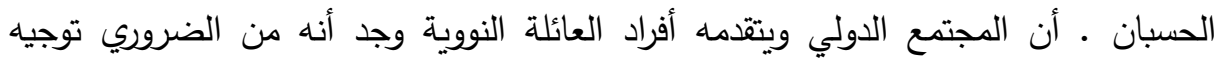

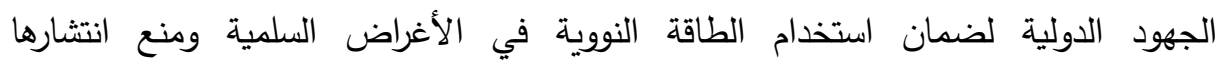
واستخدامها في الأغراض العسكرية فمن جهة لحماية الأرض والبشرية من فتلك الأسلحة

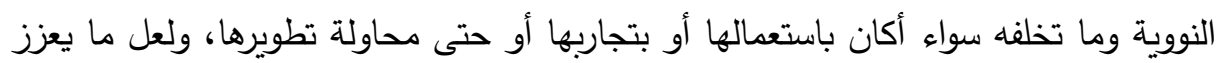

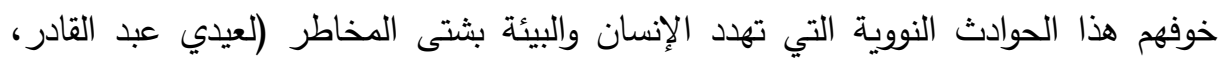
$\cdot(r \cdot 11$

\section{and Illan}

تتحصر المشكلة في عدم وضوح تأثير الضمانات والتأمنيات الخاصة بالعاملين في المنثأت النووية، مما يمثل وضعأ غير مرغوب فيه ضمن هذه المنثآت في مصرح، حيث حيث التوسع في الطاقة النووية من خلال إقامة محطات نووية جديدة، الثئ الذي قد يؤثر على فئى العاملين في هذا المجال وعلى المنشآت نفسها وقد يكون على المجتمع ككل، وما بين مؤيد ومعارض لاستخدام الطاقة النووية للأغراض السلمية وما بين تنظيم، والحد من انتثار

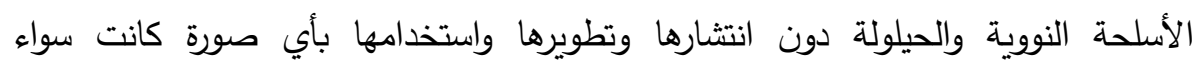

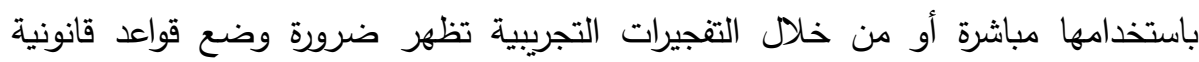
للمسؤولية الدولية الناتجة عن الأضرار النووية التي تتجم عن الأنشطة النووية للدولة أكانت

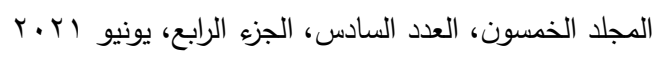

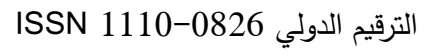


تلك النشاطات سلمية مشروعة أو عسكرية، وتطوير هذه القواعد الخاصة بالمسؤولية الدولية

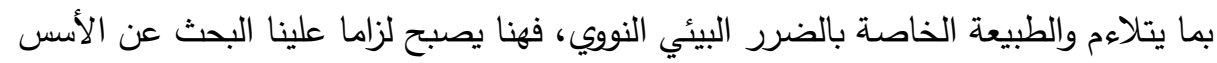

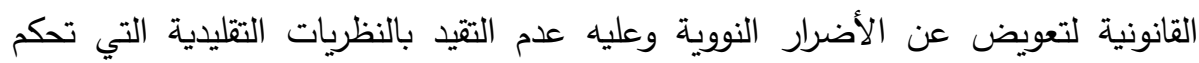

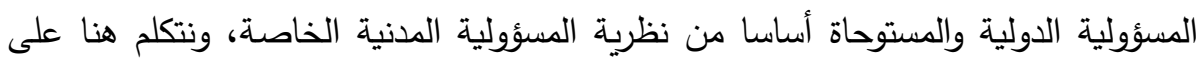

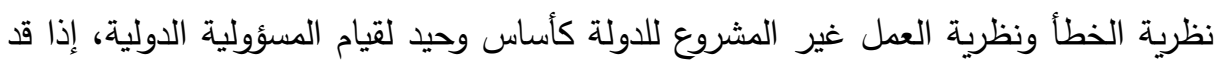
يترتب على النشاطات المشروعة للدولة أضرار شديدة ومدمرة قد تصيب الأفراد والبيئة

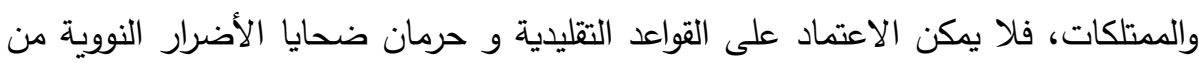

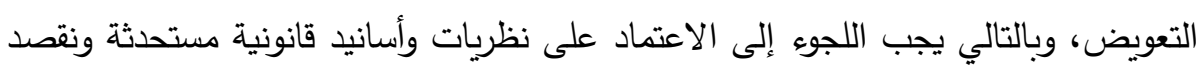

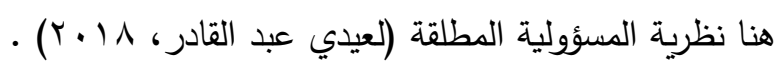
لذا يجب العمل على توفير ضمانات وتأمينات كافية للعمل في هذا المجال والعاملين

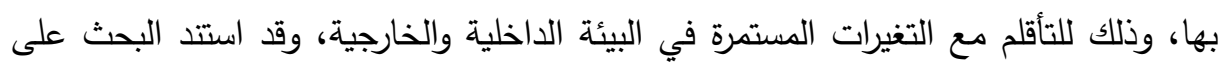

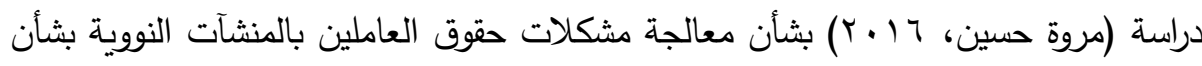

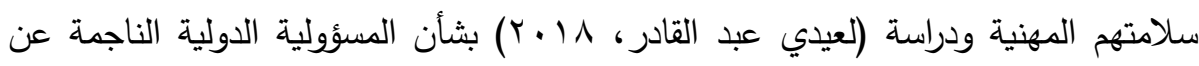
أضرار الثلوث النووي، وهذا يقودنا إلى س ؤال جوهري الا وهو مدى تأثير الضمانات والتأمينات على اداء العاملين في المنشآت النووية وفقا لقوانين الأنشطة النووية والبيئية في 


$$
\begin{aligned}
& \text { مجلة العلوم البيئية } \\
& \text { معهد الدراسات والبحوث البيئية - جامعة عين شمس لئية } \\
& \text { أروى حسين محد صلاح مكاوى وآخرون }
\end{aligned}
$$

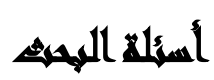

1- القا القوانين والمعاهدات والاتفاقيات المنظمة للمنثآت النووية والعاملين بها؟

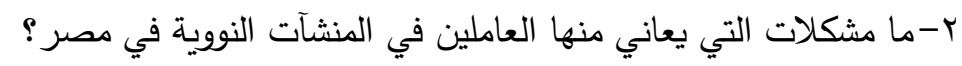

r-ما الضمانات الموجودة للعاملين في المنشآت النووية في مصر؟

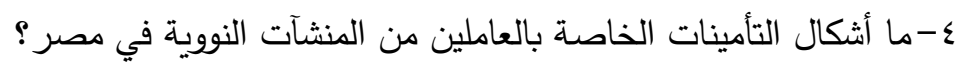

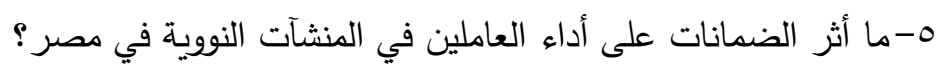

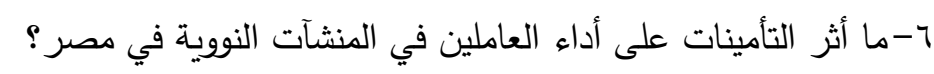

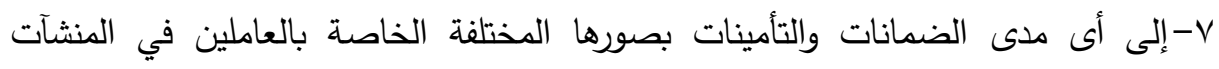
النووية في مصر كافية أم لا؟ مدى الت ولان

\section{أهماهن المبهن}

يسعي البحث إلى تحقيق هدف رئيسي وهو قياس أثر الضمانات والتأمينات على فئى

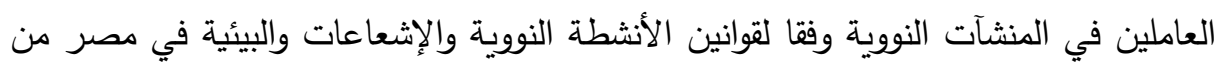
خلال تحقيق مجموعة من الأهداف الفرعية وهي:

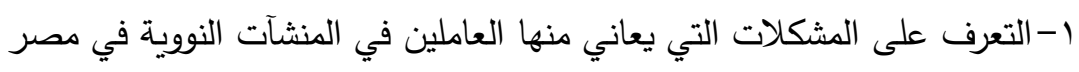

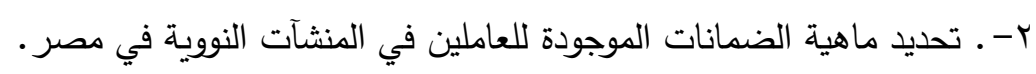
r-قياس أثر الضمانات والتأمينات على أداء العاملين في المنشآت النووية في مصر .

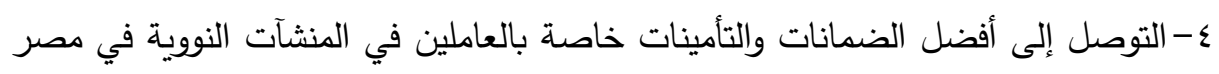
أفضل إن أمكن، وتسليط الضوء على طبيعة أعمال المنشآت النووية في مصر .

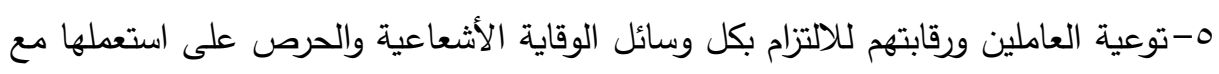
وضع الاجراءات الملزمة لتحقيق ذلك.

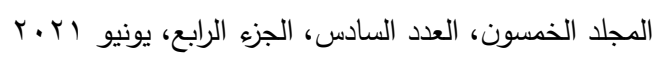

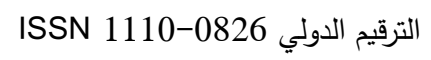




$$
\begin{aligned}
& \text { مجلة العلوم البيئية } \\
& \text { معهد الدراسات والبحوث البيئية - جامعة عين شمس لئية } \\
& \text { أروى حسين محد صلاح مكاوى وآخرون }
\end{aligned}
$$

ج-تسليط الضوء على الآثار البيئية المحتملة في المنشآت النووية وتأثيرها على العاملين بها

$$
\text { وعلى المحيط الحيوي بأسره . }
$$

\section{أهمية المهيث}

تتبع أهمية البحث من كونه يتتاول موضوع الضمانات والتأمينات خاصة بالعاملين في

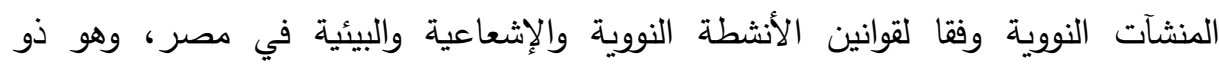
خصوصية عالية وتأثير كبير على مستوي حياة الأفراد والمنشآت النووية والدولة بشكل عام الإنين وبسبب أهميته في الوقت الراهن ومدى تأثير كبير على مستوى حالة الأفراد والمنثآت النووية

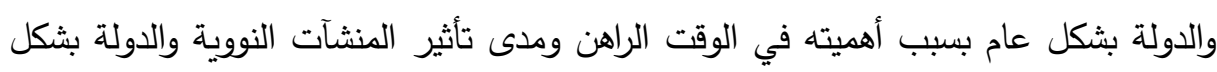

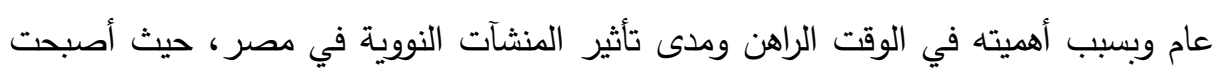

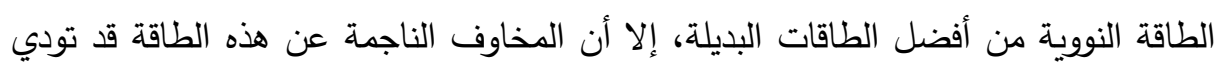
بحياة البشرية.

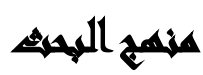

يعتمد البحث على المنهج الوصفي التحليلي الذي يتضمن استخدام الأسلوب الميداني في

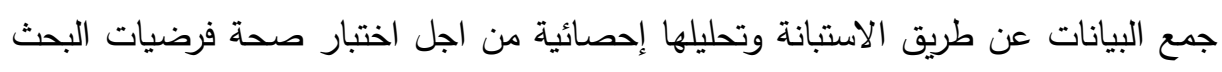

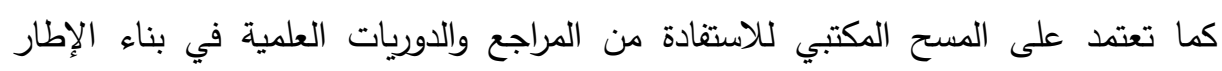
النظري.

$$
\begin{gathered}
\text { المجلد الخمسون، العدد السادس، الجزء الرابع، يونيو الترقيم الدولي 0826-0 } \\
\text { ISSN 1110 }
\end{gathered}
$$




$$
\begin{aligned}
& \text { مجلة العلوم البيئية } \\
& \text { معهد الدراسات والبحوث البيئية - جامعة عين شمس البية } \\
& \text { أروى حسين محمد صلاح مكاوى وآخرون }
\end{aligned}
$$

\section{هزغ المهنه}

يقوم هذا البحث على فرض رئيس والذى ينص على " لا توجد علاقة جوهرية ذات

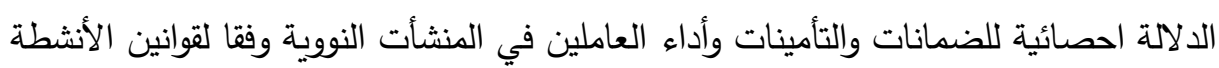
النووية والإشعاعية والبيئية في مصر " .

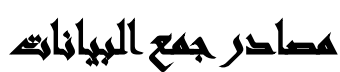 \\ سيتم الاعتماد في هذا البحث على عدة مصادر لجمع المعلومات:}

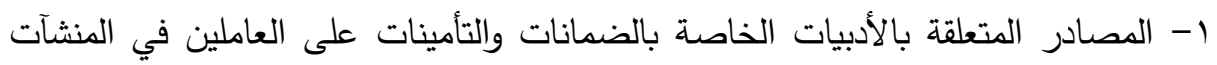
النووية وفقأ القوانين الأنشطة النووية والإثعاعية والبيئية في مصر مع الاستعانة بالأنماط

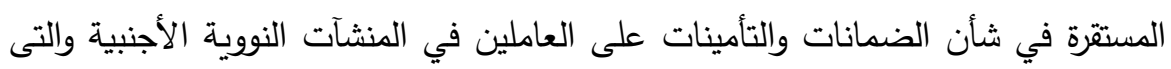

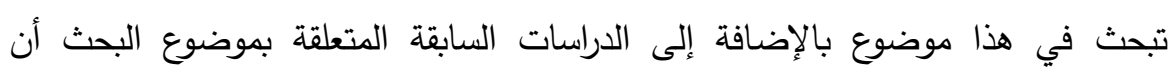

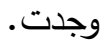

r- القوانين الخاصة بالأنشطة النووية والإشعاعية والبيئية المصرية والدولية . r- الإتفاقات الدولية توصيات التجمعات الإقليمية ذات الصلة.

ع - المصادر الأولية، والتي اعتمدت على البيانات التي سيتم جمعها من أفراد عينة البحث وكذلك المقابلات الثخصية للمسئولين.

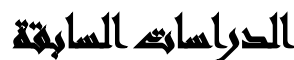

تثكل موضوعات الطاقة والتتمية المستدامة ملف حديث الولادة بالنسبة لدول العربية، حيث تتبلور إتجاهاتها لضمان توافر موارد طبيعية ومصادر وفيرة لأجيال المستقبلية وبناء

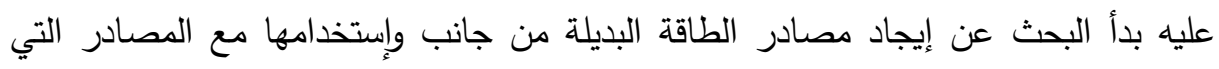

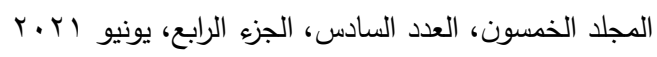

$$
\begin{aligned}
& \text { الترقيم الدولي 0826- ISSN 1110 }
\end{aligned}
$$


توشك على النضوب من جانب اخر، أملا في إبقاء نصيب الأجيال اللاحقة، وذلك في كل مناحي الحياة من الغذاء والطاقة والصحة والتلوث البوث البيئة وغيرها.

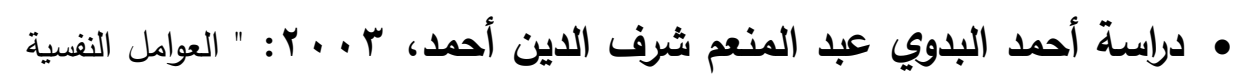

المرتبطة بالحوادث الإثعاعية في مجال التطبيقات السلمية للطاقة الذرية"

تتاولت هذه الدراسة العوامل التي يتأثر بها العاملين في حالة حدوث حادثة إثعاعية،

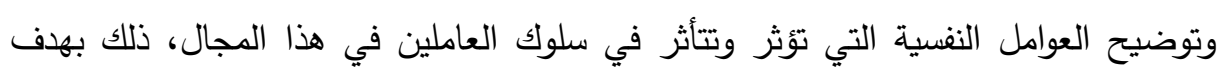

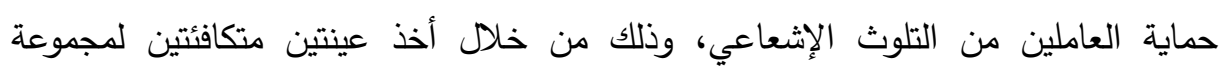

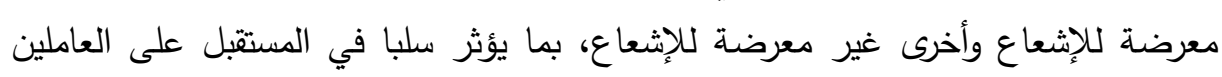
بالمنظومات النووية

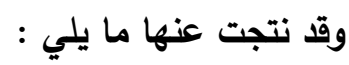

ا- وجود فروق معنوية بين العينتين، كانت في صالح العينة غير المعرضة للإشعاع، مما

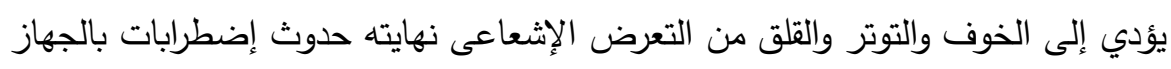

$$
\text { العصبي للجسم العامل }
$$

ץ- إنخفاض المستوى المعرفي لدى العاملين بالمجال الإثعاعي مما يزيد من الأخطاء

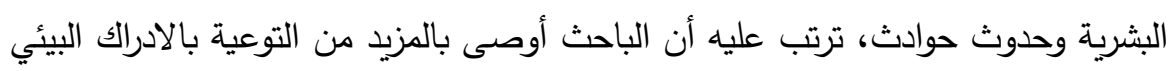

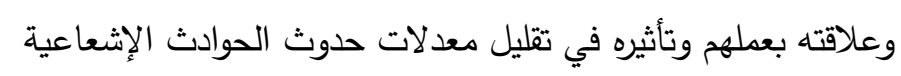

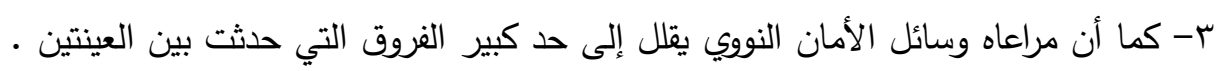
كما أوصت الدراسة بالتدريب العاملين في المنظومات الإثعاعية، والمتابعة الدورية بالكثف المستمر على العاملين داخل المجال الإثعاعي من النواحي النفسية وإجراء المزيد

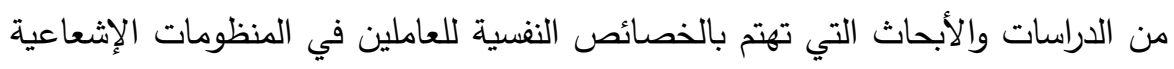
بغرض رفع كفاءة العاملين وزيادة أدائهم النفسي بما ينعكس على سير العمل في تلك لكابك

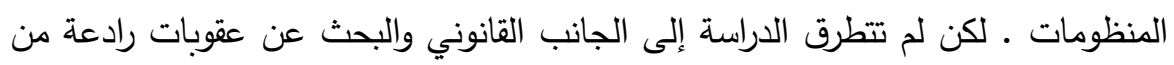

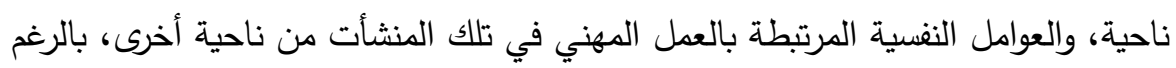
404

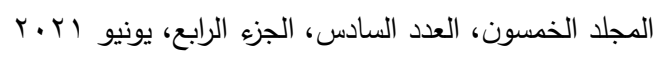

$$
\begin{aligned}
& \text { الترقيم الدولي 0826- ISSN 1110 }
\end{aligned}
$$




$$
\begin{aligned}
& \text { مجلة العلوم البيئية } \\
& \text { معهد الدراسات والبحوث البيئية - جامعة عين شمس البية } \\
& \text { أروى حسين محمد صلاح مكاوى وآخرون }
\end{aligned}
$$

من أهميته على الأداء الإداري والرضا الوظيفي لدى العاملين الذي يرتد إنعكاسه على رفعه المجال النووي بأسره.

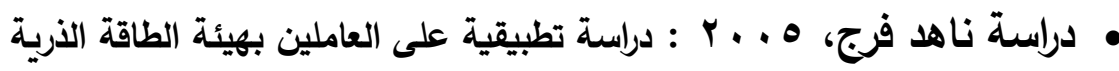

\section{استهدفت هذه الاراسة هدفين هما :}

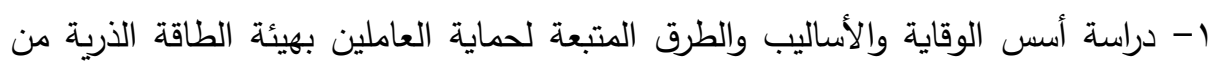
التلوث الإثعاعي، وأهم العوامل التي تؤثر على كفاءة استعداد الجهات العاملة في المجال

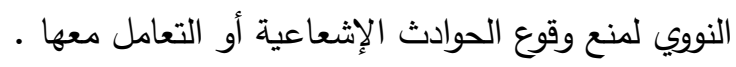

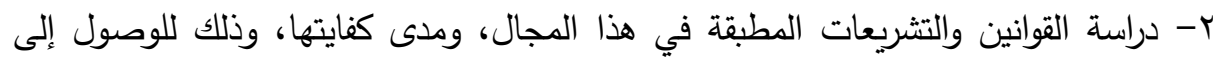
أقصى درجات الحماية والوقاية، والتعويضات المناسبة في حالة الإصابة بالتلوث الإثعاعى، وبناء على الأهداف توصلت الباحثة إلى عده نتائج من شأنها تطوير القواعد القانونية والقوانين الخاصة بتعويض العاملين في مجال الإستخدامات السلمية، كما نتجت التهاء إلى أن القانون المدني هو الطريق لتعويض العمال المضرورين بالإشعاع. ومن دراستها التطبيقية على العاملين بهيئة الطاقة الذرية وجدت أنه ينقص أساليب الوقاية وحماية العاملين من الإثعاعات إلزام تطبيقها والجدية لإجراء الفحوصات الطبية الدورية، وعدم الإهتمام بالوعي المهني والقانوني بالنسبة لمهام العاملين داخل هيئة الطاقة الذرية، وضرورة تحديث القوانين بما يناسب الطبيعة الخاصة لأنشطة النووية . إلا أن هذه الدراسة أغلقت أبواب الاستبيان عن المواطنين العاديين و المصابين بأضرار

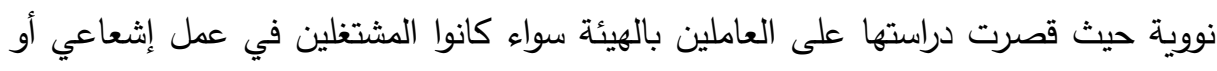

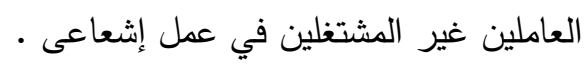

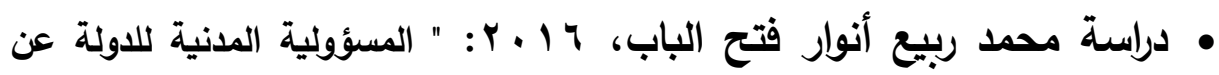

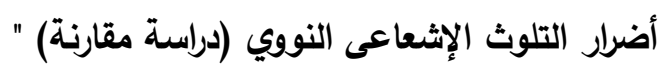

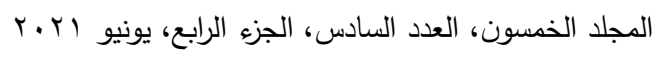

$$
\begin{aligned}
& \text { الترقيم الدولي 0826-0SN 1110 }
\end{aligned}
$$


تكمن أهمية الدراسة في تحديد طبيعة النظام القانوني الذي يهدف إلى حماية المضرورين من جراء الأضرار التلوث الإشعاعي النووي، كما تهدف الدراسة إلى البحث عن مدى ملائمة

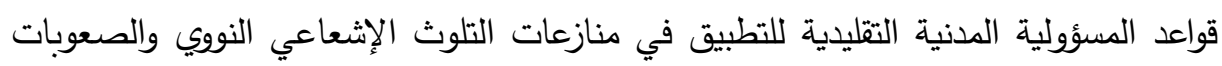
التي اكتنفت تطبيقها والعقبات التي واجهتها من حيث مدى إمكانية توافر الأركان الرئسية،

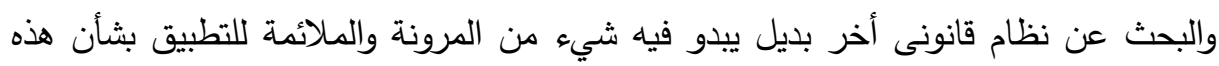

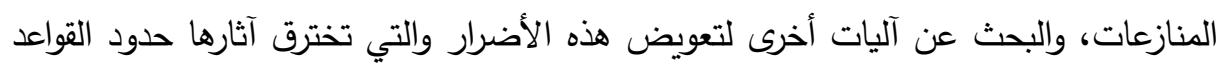

$$
\text { العامة في التعويض. }
$$

وتوصلت إلى النظام القانوني الاستثنائي للمسؤولية المدنية عن الأضرار النووية على

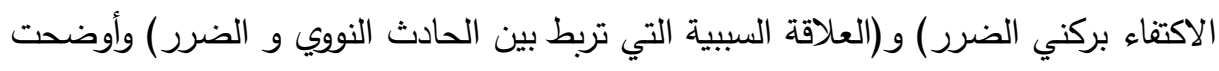

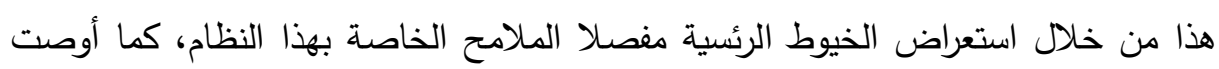

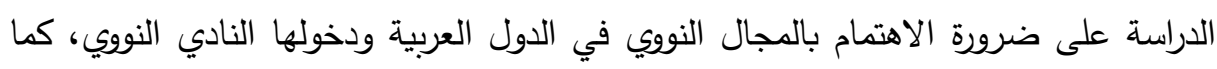

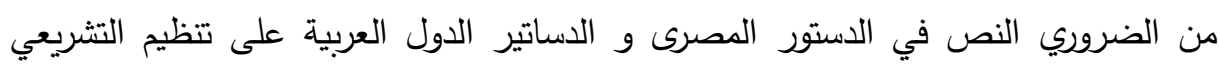
النووى .

\section{• دراسة مروة حسين محمد صلاح، 1 ـ ـ ب: " إطار مقترح لمعالجة مشكلات}

\section{حقوق العاملين بالمنثآت النووية بشأن سلامتهم المهنية "}

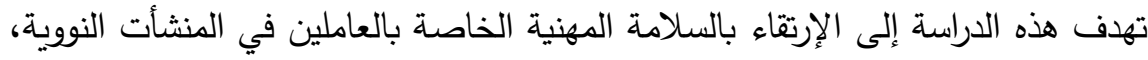

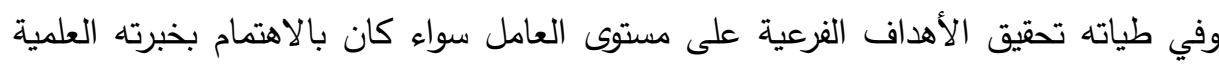

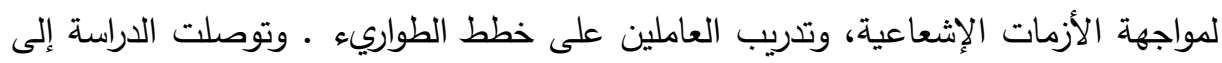

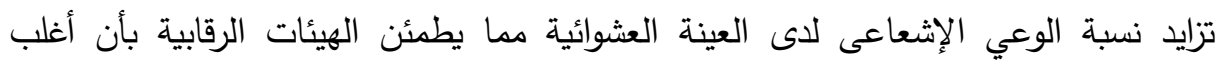

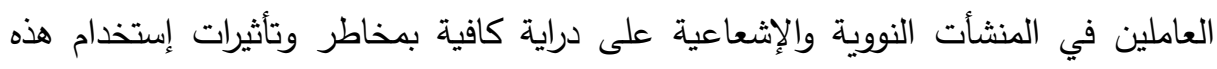

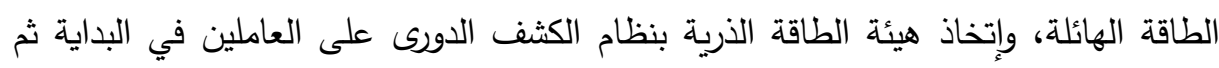

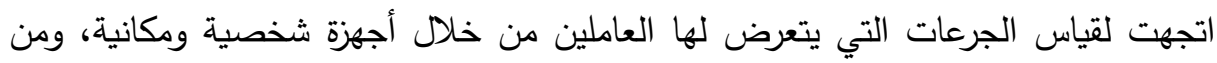
ضمن النتائج أن الهيئات النووية أخذت بنظام الخطط المعده مسبقأ لهنع حدوث كوارث وكيفية 406

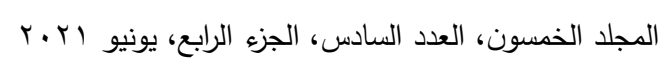

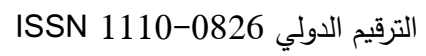


إدارة الأزمة، بجانب المشاركة الثعبية عند وضعها من أجل حماية الإنسان والبيئة، كما حددت الجهة التي تختص بالرقابة، إلا أن هذه الدراسة لم تغطى الجانب النفسي العائد على التى

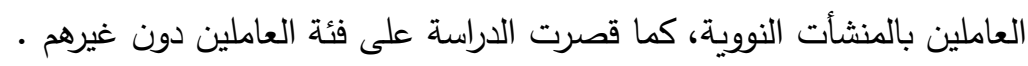

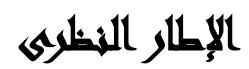 \\ فيما يلى إستعراض لبعض المصطلحات المستخدمة فى البحث}

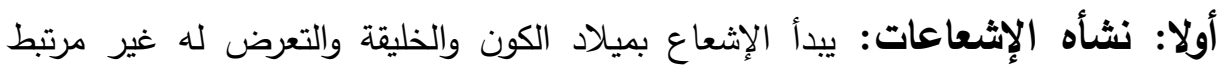
بالإرادة الإنسان أي يتعرض الإنسان الإثعاع شاء أم أبى، فلا مفر من الإشعاع القادم من

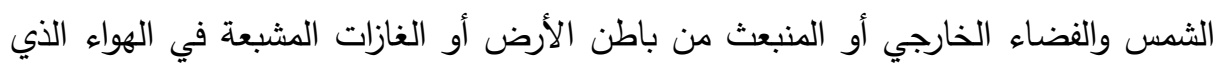

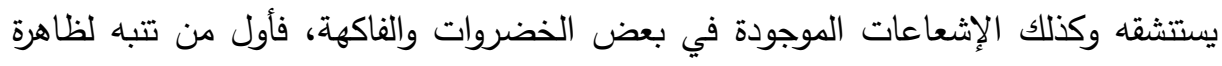

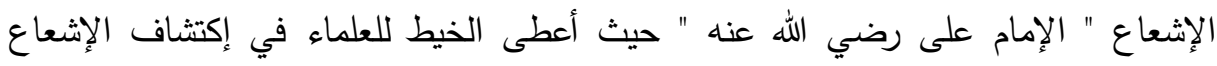
والمرض الإشعاعي وكيفية معالجتة والوقاية من هذا المرض، وذلك من خلال قوله "رضي الله

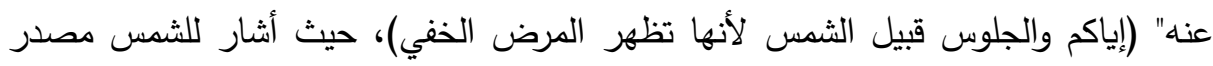

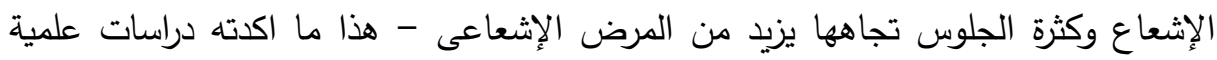

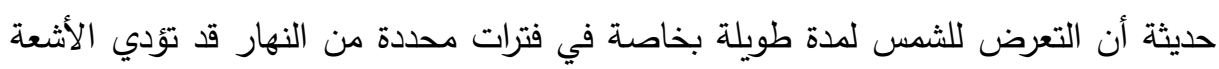

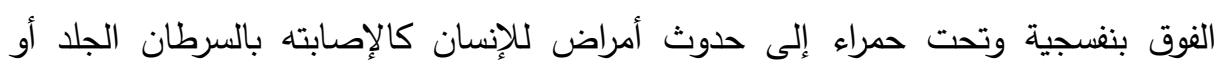

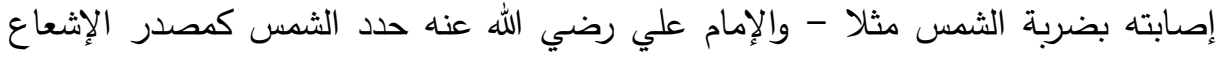
بإعتبارها من أهم المصادر الرئيسية الطبيعية التي يتعرض إليها الإنسان لها يوميا تقريباً (ناهد

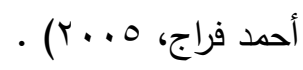
ثانياً: تعريف الإثعاعات النووية: بعد أن أبحرنا في رحلة الإكتثاف الذرى، يمكن

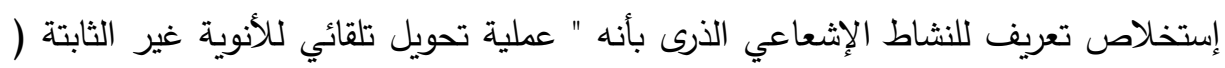

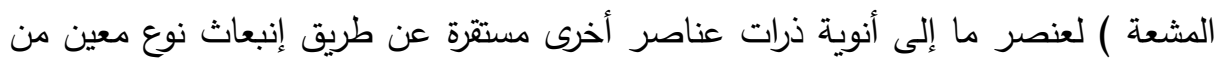


الإشعاع (سيد عيد نايل، ه . . r)، ومجرد لفظ الإشعاع يندرج تحته الضوء سواء من الثمس

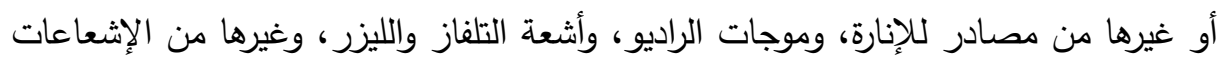

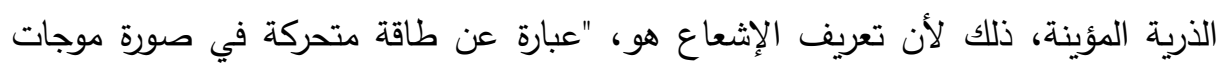

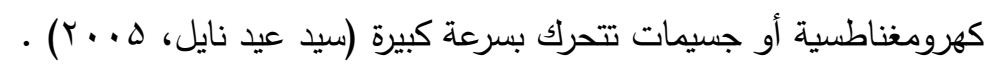

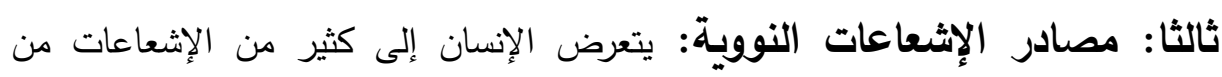

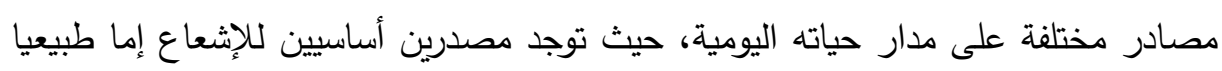

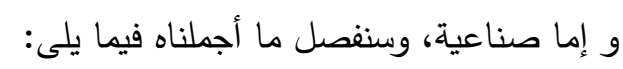
1 - المصادر الطبيعية: الإنسان يعيش وسط الإثعاعات فتحيط به من كل جانب من من أشعة

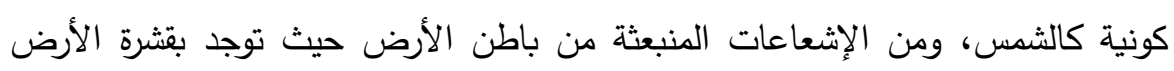

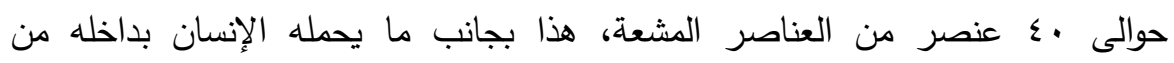

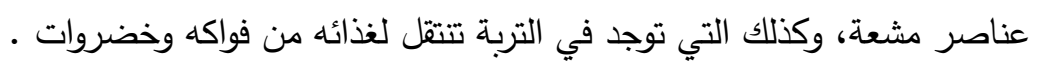

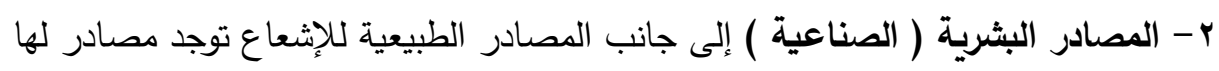

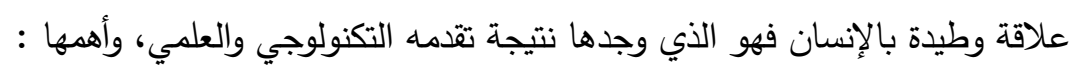

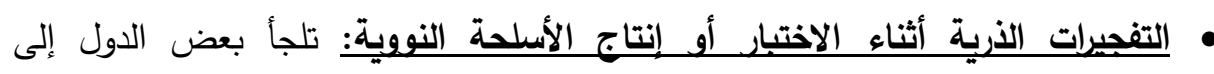

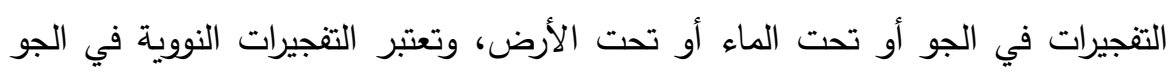
أكثر تأثيرا في التلوث البيئي حيث ينتج منها العديد من المخلفات والعناصر المشعة التي تتحد مع راب الأرض و الغبار العالق في الهواء و بخار الماء مكونه (الغبار الذرى) و(الأمطار الذرية) والتي تثكل خطرا على سكان الأرض حيث تستمر موجودة سنين

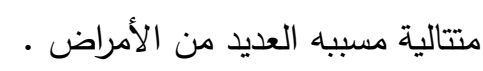

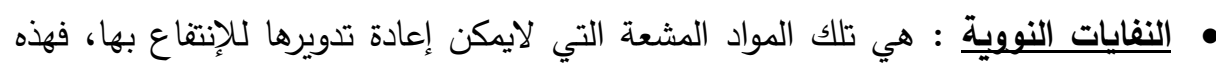

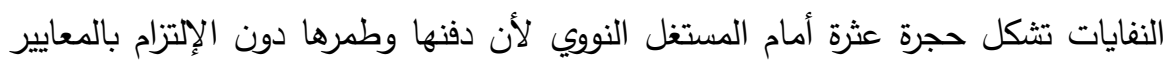

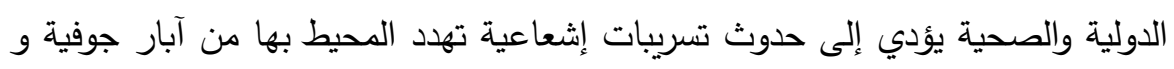

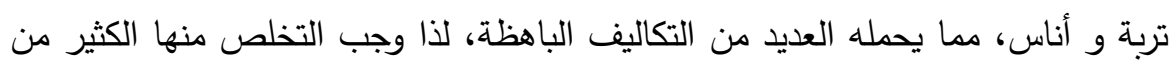
408

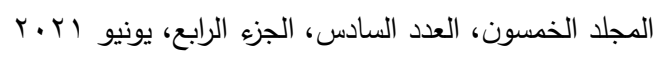

$$
\begin{aligned}
& \text { الترقيم الدولي 0826- ISSN 1110 }
\end{aligned}
$$


الإحتياطات والضمانات التي تنظم طريقة تخزينها ودفنها وكذلك إختيار المكان المناسب غير المعبيء بالسكان لضمان سلامتهم • المفاعلات النووية : الآن تعد منارة الدول المتقدمة و السابحة في نهر التمية والتقدم، لأن أغلب المفاعلات النووية تستخدم في محطات الكهرباء للإنتاج طاقة نووية أرخص وأنظف، وهذا بجانب دور المفاعلات النووية في البحث العلمي الذي أضاف الكثير للعلم، بيد أن التعرض للإشعاعات قد يكون مهني بمعنى إقتصاره على العاملين والخبراء الفنيين والفيزيائيين . • نقل المواد النووية: تحوي عملية نقل المواد النووية المشعة على خطر داهم في التعامل مع الإثعاعات المؤينة مما يسبب أضرار بالغة للقائمين بهده العملية، وبخاصة عمليات الثحن و التفريغ اليدوية نظرا لأن الخطورة تكون أقرب للأفراد العاملين منها إذا كانت العملية اليه. • إستخدام النظائر المشعة: في الواقع أصبح مجال إستخدام النظائر المشعة حافل بإنجازات

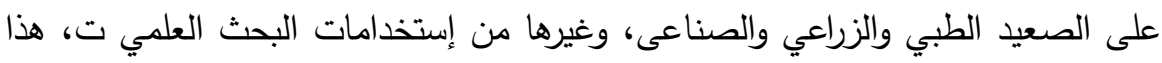

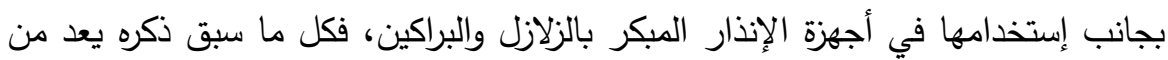

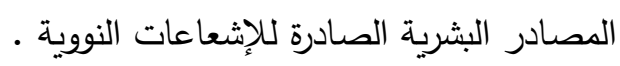

ثالثاً: أنواع الإشعاعات: قسم الإشعاعات بحسب درجة الخطورة التي تكمن فيها ومدى لألثى تأثيرها على الأجسام، فيوجد لهذه الإشعاعات نوعين رئسيين هما :

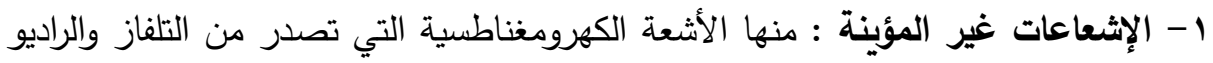

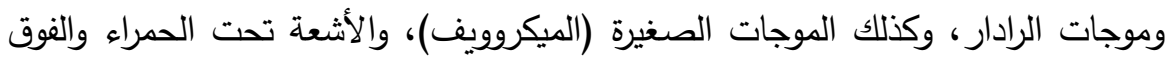

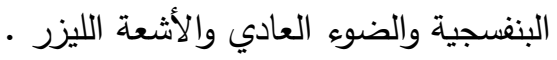
r- الإثعاعات المؤينة : هي الإشعاعات تتبعث من النوبات غير المستقرة من أجل تحولها

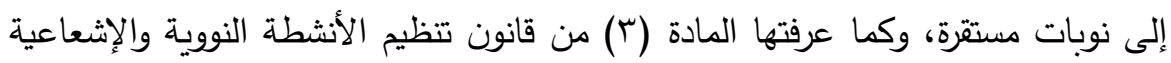

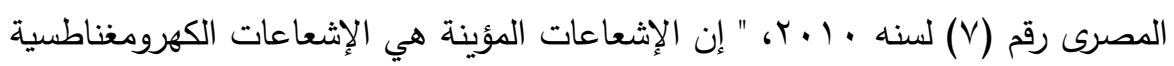

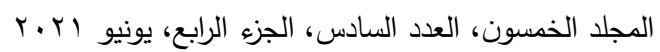

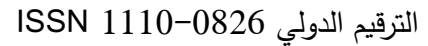


أو الجسمية القادرة على الإثارة والتأيين الذرات أو جزيئات المادة عند إختراقها ومنها

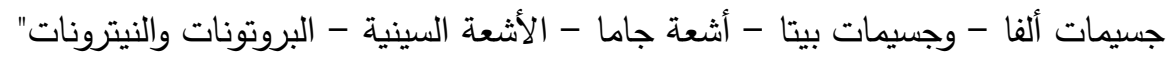
أ- أشعة ألفا : هي عبارة عن جسيمات موجبة الثحنة الكهربائية، وكل جسيم منها يتكون من نواة الهليوم المكونة من بروتونين ونيترونين ومن ثم فهي تحمل شحنتين موجبتين ونظرا

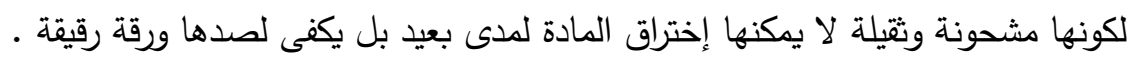

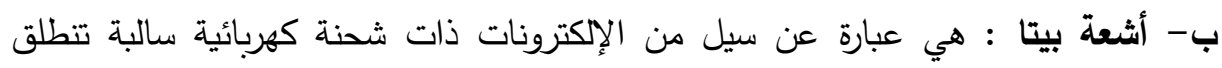

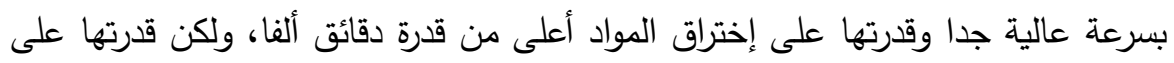

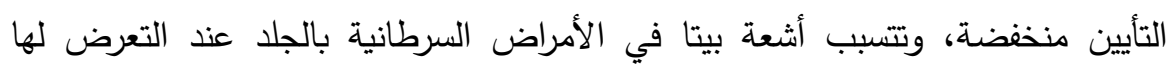
خارجية وتزداد خطورتها عند البلع المادة التي تتبعث منها تلك الأشعة (محمد ربيع فتح

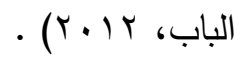

ج- أشعة جاما : هي عبارة عن موجات كهرومغناطسية ليس لها شحنة كهربائية تتبعث أثناء التفاعلات النووية وكذلك عندما تتحلل بعض أنوية العناصر إثعاعية، فهي تقابل سرعة

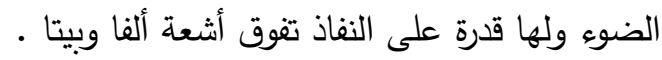
د- الأثعة السينية : هي عبارة عن موجات كهرومغناطسية مثل أثعة جاما ولكنها ذات طاقة أقل منها، ويستخدم هذا النوع من الإثعاعات في إجراء الفحوص الطبية والتثخيصية المختلفة وفي بعض الصناعات . و - النيترونات : هي عبارة عن جسيمات متعادلة الثحنة الكهربائية تصدر من الإنشطار

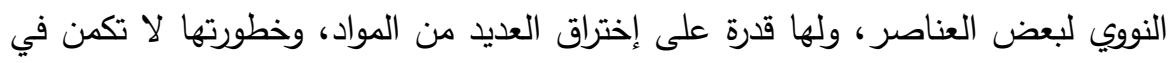

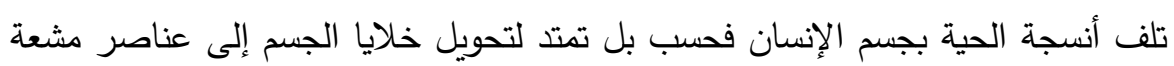
تصدر العديد من الإثعاعات كألفا وبيتا وجاما داخل الجسم نفسه مما لها أضرار بليغة 
رابعاً: خصائص الإشعاعات النووية : تختلف خصائص الإشعاعات النووية عن غيرها، مما يضفي عليها هالة خاصة تميزها من الجانب القانوني سواء كان على المستوى التشريعات

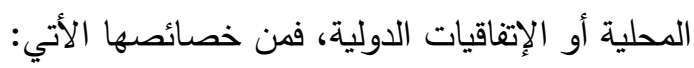
• لا يستتبطها الإنسان بحواسه كرؤيتها أو شمها أو تذوقها حيث ألهات أنها عديمة اللون والرائحة

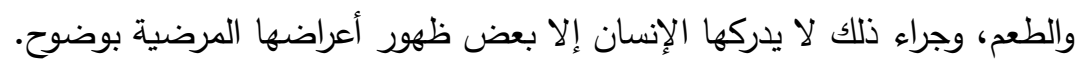
• تتميز بتسلل آثارها عبر الزمان، فلا يقتصر أذاها وضررها على الكائنات التي تعرضت لإنت لمثل الإشعاعات النووية بل تظل ممتدة الأثر على مدار أجيال متتالية مهددة خصائصهم الوراثية . • الحدود الجغرافية لا تقف عائقا إزاء آثارها، فهي واسعة الانتشار والتوغل في البلاد والقارات، فإذا حدثت كارثة نووية فهي تهدد العالم بأسره بأخطارها

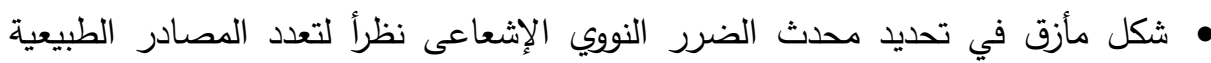
والصناعية، وبتالي يصعب تحديد العلاقة السببية • إن التعرض الإشعاعات النووية تتميز بصفة التراكم للجرعات في الجسم المستقبل

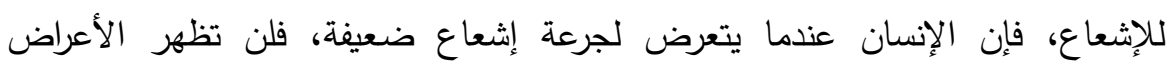

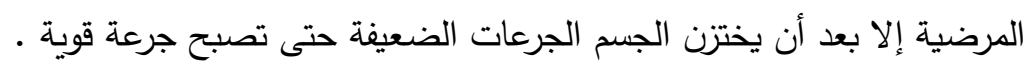

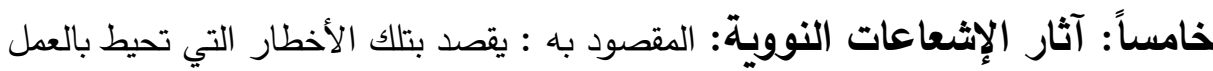
النووي والإشعاعي، وبعبارة أخرى هي إحتمالية حدوث ضرر جراء التعرض للإشعاعات المؤينة سواء تثكل على هيئة مرض أو إصابة أو الوفاة . 1- التأثيرات البيولوجية: هي تلك الأخطار التي محلها الكائنات الحية عموما والإنسان بصفة إنة التهاة خاصة، فعند تعرض أي إنسان للإثعاع المؤين يتم إختراق جسده للوصول لأنسجة

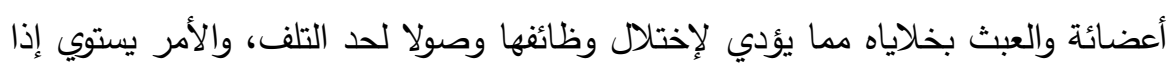

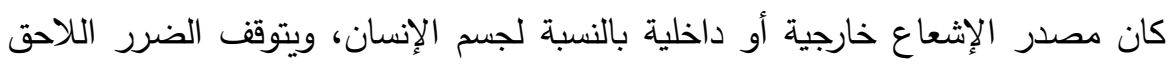

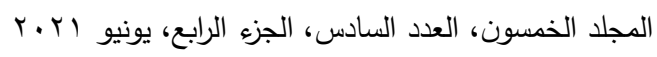

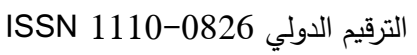


بالإنسان على مقدار الجرعة وحساسية العضو الذي تعرض للإشعاع المؤين ومدة التعرض، و تظهر التأثيرات البيولوجية في صورة أعراض مرضية أو ما يسمى (بالأعراض لإنسان

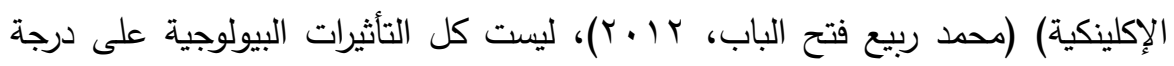

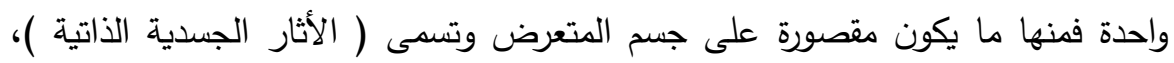

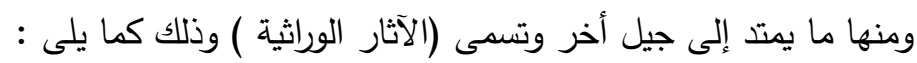

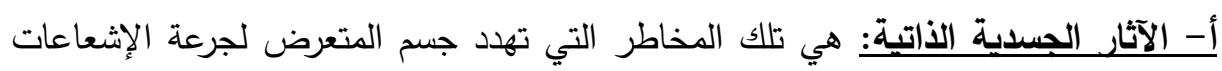
المؤينة وتختلف في ظهورها حسبا المدة التي تعرض إليها، فهناك علاقة طردية تربط بين

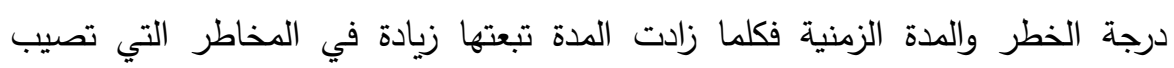

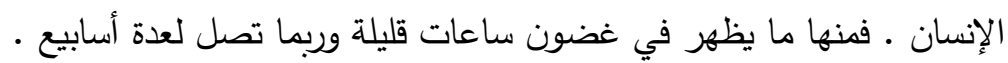
ب- الآثار الوياثية : تلك التأثيرات البيولوجية تصيب خلف فئف من تعرض للإشعاعات فنظهر العيوب الخلقية في الأجيال المتعاقبة قد تستمر إلى جيلين، مما ينتج أجيال مليئة

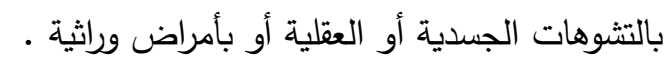

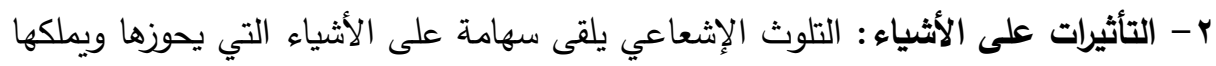

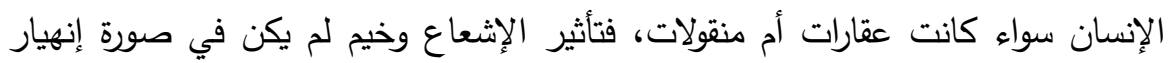
مادى وهلاك لشيء بل أشد حيث يحول الجسم إلى مصدر للإثعاع مما يتسبب في أثار وخيمة يترتب عليها عدم صلاحيته للإستخدام، وتكتنف الصعوبة في تحديد مقدار الإثعاع الكامن به وتطهير الثيء المعبيه بالإشعاعات يكلف مبالغ باعظة تقف عائقا أمام البعض. سادساً: إستخدامات الإثعاعات المؤينة: صارت الطاقة النووية والنظائر المشعة محط أنظار الجميع وحديث الساعة، بعد أن نسجت خيوطها في كثير من المجالات السلمية،

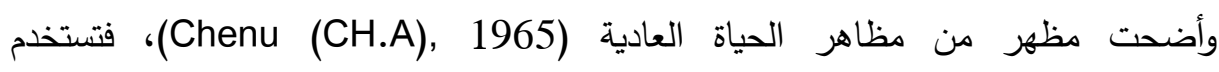
الإشعاعات النووية على سبيل المثال وليس الحصر في مجالات الطب والزراعة والصناعة

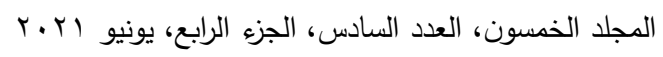

$$
\begin{aligned}
& \text { الترقيم الدولي 0826-0 }
\end{aligned}
$$


والأبحاث العلمية وذلك بجانب دورها في توليد الكهرباء، فسوف نعرض نبذة عن إستخداماتها

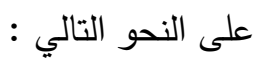
ا- المجال الطبي : تتعدد أدوار الطبية للإشعاعات النووية فتقوم بالدور الوقائي لتفادي

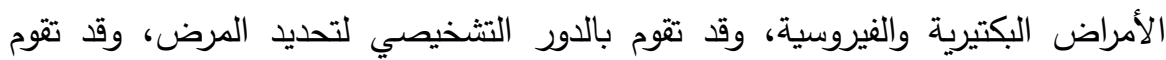
بالدور العلاجي، وذلك بجانب أنها قد سبب الأمراض التي تعالجها مثل السرطان، فإن

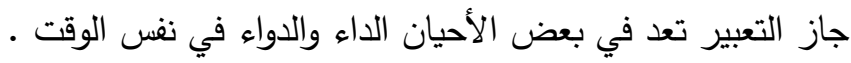
r- المجال الصناعي: تستخدم تكنولوجيا الإشعاع في مجال الصناعة بهدف تحسين مواصفات المنتجات الصناعية، فيستخدم الإثعاع في المنسوجات القطنية من أجل ضمان جودتها (أيمن محمد سليمان، ب. . . )، كما يدخل في الصناعات الزجاجية بواسطة الليزر الذي يدخل في صناعات عديدة .

r- مجال توليد الطاقة : تجلى دور الإشعاعات المؤينة في توليد الطاقة النظيفة بعد أن أن أنداء

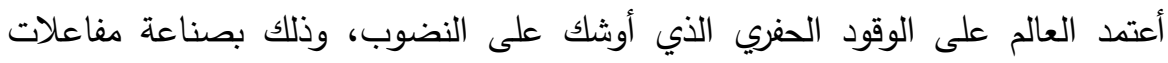
نووية كانت في باديء الأمر يعمل بالماء العادي المضغوط الذي تطور بإستخدام الماء المغلي وصولا إلى المفاعلات الماء البارد (الجيل الرابع) للحد من عيوب الألئ بأنواع السابقة. ـ - مجال البحث العلمي : إن الإشعاعات النووية لم تصل إلى منتهاها في البحث العلمي، فتم فتح الباب أمام الأبحاث العلمية على مصراعيه بواسطة الإشعاعات النووية والنظائر المشعة، فلها دور مباشر في الإكتشافات العلمية الحديثة مثل علم الوراثة والبحوث البيولوجية . سابعاً: العوامل المسببة في وقوع الحوادث الإثعاعية: تتعدد أسباب نشوء الحوادث الإشعاعية فقد تتنج عن إخلال بواجبات الوظيفية أو عن قصور في الجانب الفني أو غيرها من الأسباب الثخصية على النحو التالي : 1 - عدم كفاية الرقابة التظظية: يعتبر هذا السبب من الأسباب الهامة للحوادث في العديد

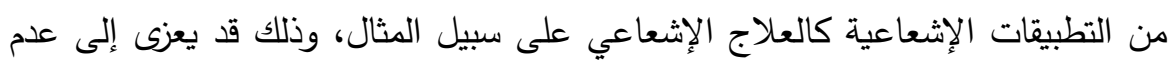

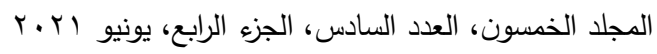

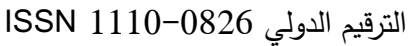




$$
\begin{aligned}
& \text { مجلة العلوم البيئية } \\
& \text { معهد الدراسات والبحوث البيئية - جامعة عين شمس لئن } \\
& \text { أروى حسين محمد صلاح مكاوى وآخرون }
\end{aligned}
$$

وجود سلطة تنظمية نووية في الدولة أو وجود تلك السلطة ولكن بصورة غير فعالة وكذلك

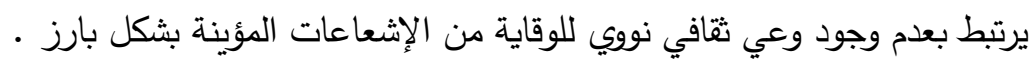

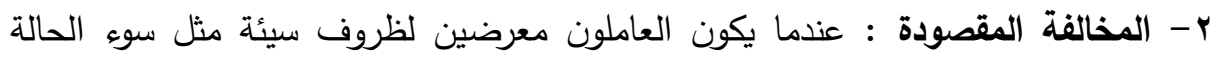

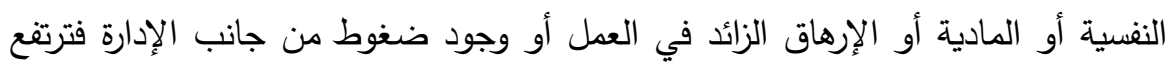

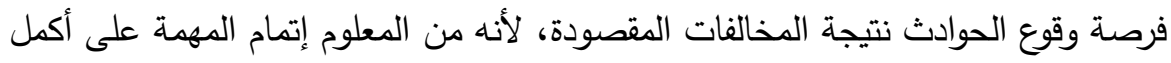

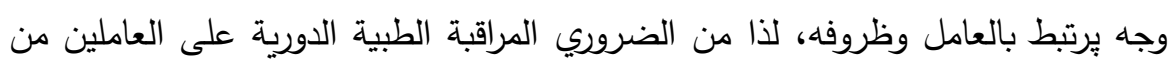

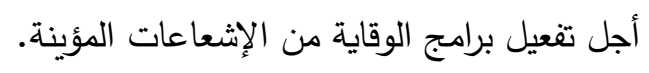

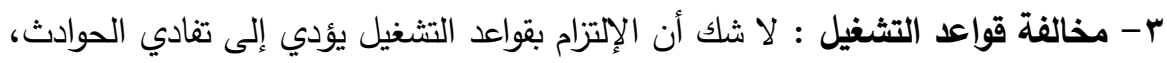
ولعل من الأسباب الرئيسية في وقوع حادث ما هو غض العض العامل عن المخالفات وربما التهاون الذي يحدثه المشرفون والمدربون تجاه العاملين الذين لا يملكون خبرة كافية أو غير فير

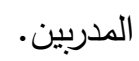

؟ - الأخطاء البشرية: لا يوجد مجال يخلو من الأخطاء البشرية، فبرغم من مبادرة الإنسان

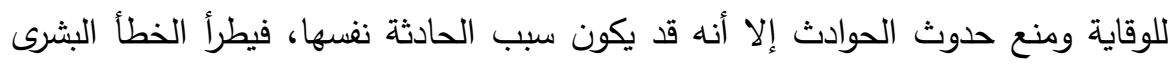

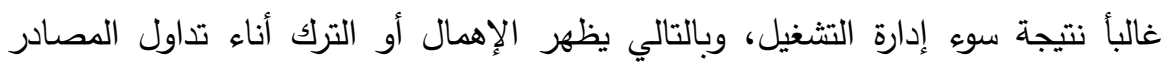
المشعة .

ه- نقص التدربب: يعد التدريب مفتاح التقدم وديمومته، فنقص التدريب في أي عملية مرتبطة

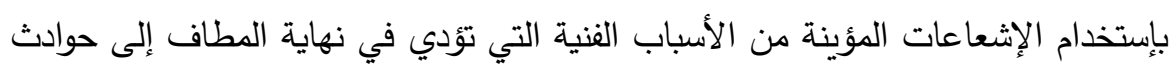

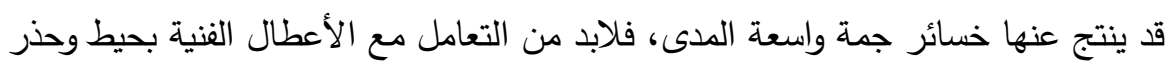

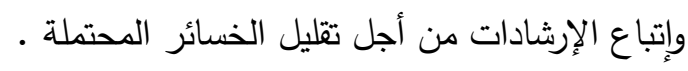

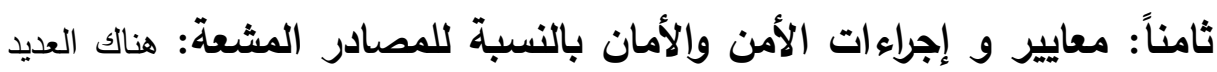

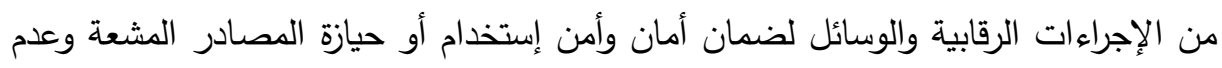
التأثير سلبية على العاملين والجمهور والبيئة، فيمكن الإكتفاء بتفصيل إجراء ان للأكمان التان الإثعاعي على نحو التالي :

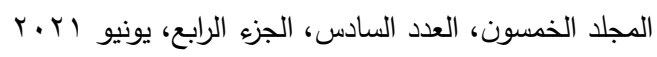

$$
\begin{aligned}
& \text { الترقيم الدولي 0826-0SN 1110 }
\end{aligned}
$$


1- الترخيص: تعد التراخيص أحد التصاريح لضمان أمان المصادر الإشعاعية عند إستخدامها في مختلف الأغراض والهدف منها حصول المستفيد النهائي سواء كان مريضا في مستشفى للعلاج بالطب النووي أو الإشعاعي، أو مشغلا لمشروع صناعي أو زراعى المانى من إستخدام المصادر المشعة من خلال أساليب صحية وآمنة مدروسة.

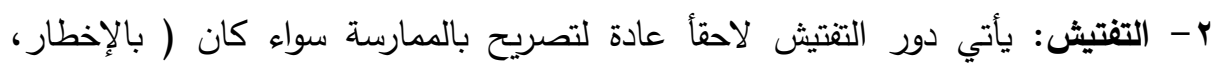

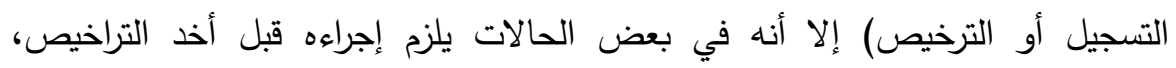

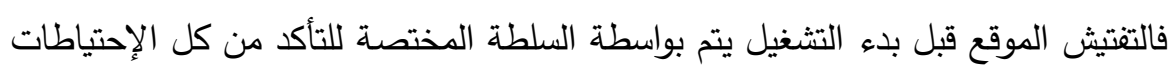

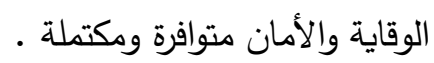
تاسعاً: دور خطط الطواريء الإثعاعية في حماية الإنسان والبيئة: تمثل خطط الطواريء

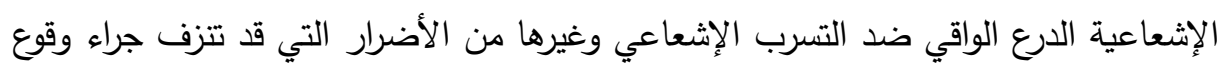

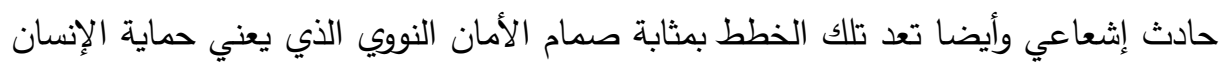
و البيئة من الأخطار والأضرار المحتملة لأي نشاط نووى والذي يهدف إلى الذى :

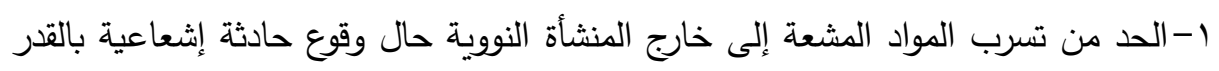
المستطاع.

ץ- الحد من تعرض السكان لأي جرعات إثعاعية تزيد عن الحد المسموح به دولية سواء عن

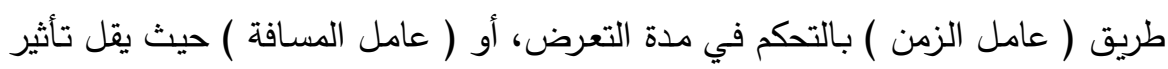

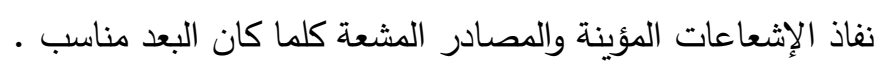

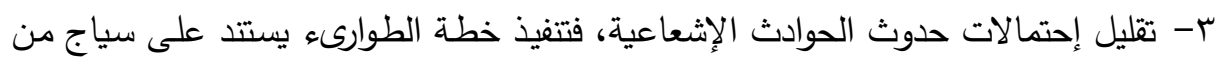

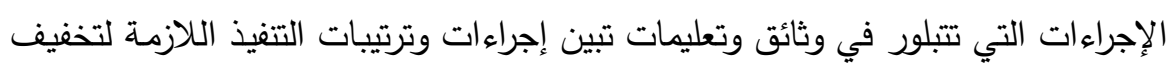

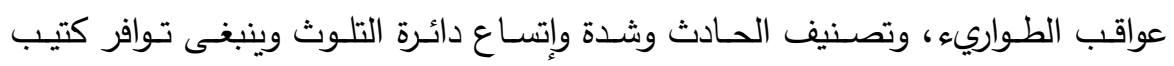

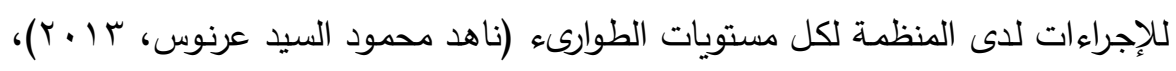
فمن أهم الإجراءات اللازمة في مرحلة الإستعداد لمجابهة الحوادث:

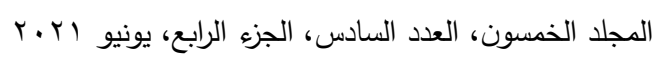

$$
\begin{aligned}
& \text { الترقيم الدولي 0826- ISSN 1110 }
\end{aligned}
$$


أ - تحديد الجهة المسؤلة عن الإبلاغ وإتخاذ القرار تحديدا واضحا لا لبس فيه، والإتفاق على نظام موحد للإبلاغ مع تحديد المعلومات المطلوب إبلاغها (الوكالة الدولية لطاقة الذرية،

$$
\cdot(-r \cdot)
$$

ب- تصميم نظام مراقبة روتيني لرصد التعرض الداخلي والخارجي لضمان توافر أمن وأمان

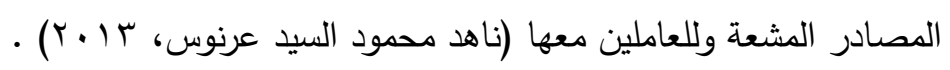

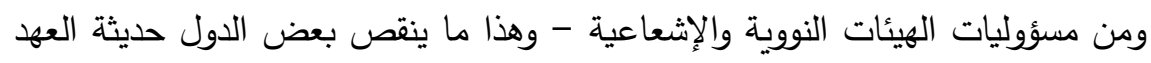
- ضمان تأمين التدريب بثكل مناسب لكل العاملين وتتفيذ تدريبات عملية على التخطيط والتأهب للطوارىه على فترات زمنية دورية، كذلك تتفيذ برامج تدريب تتشيطي بثكل مستمر

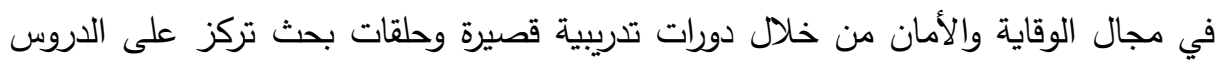

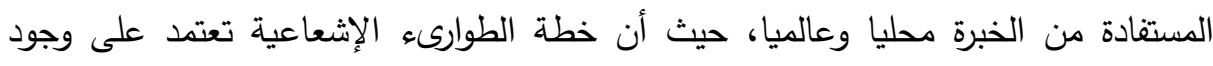
فريق مؤهل ليتولى مسؤوليات التخطيط للطواريء والإستعداد لها والتصدي لحجم الأعباء

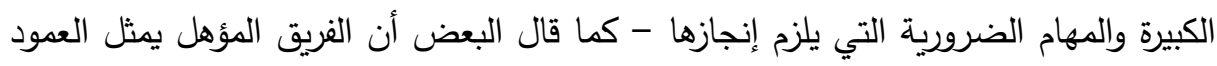

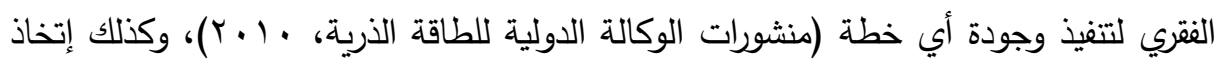
القرارات المناسبة بثأن الخطوات والإجراءات وتحديد الإلتزامات والإمكانيات وتقسيم الأدوار والمئوليات بين الأجهزة المختلفة هو المدخل الرئيسي لإعداد خطط الطوارىه الإثعاعية سواء الإهاء على المستوى الإقليمي أو بالمنثات النووية والإثعاعية بما يتتاسب مع تعليمات الوكالة

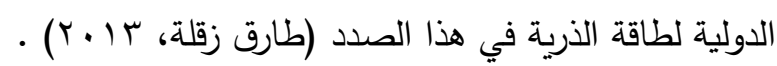
ولقد وجد أنه من أهم متطلبات الأساسية لإعداد خطة الطواريء (ناهد محمود السيد

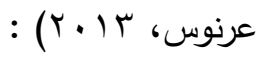
1- إعداد هيكل تتظيمي مؤهل لتتبؤ بحجم المخاطر المحتملة من الأنشطة النووية والإشعاعية r- إنتهاج أليات حديثة لتوفير الرقابة على إستخدام المنشأة للمصادر المشعة والأنظمة الفنية

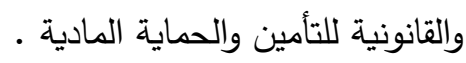


r-مراعاه إششادات الوكالة والأجهزة المعنية في الدولة والتتسيق مع باقي الإستراتيجيات كالإخلاء وخطة الإيواء والإتصال

ع-تبسيط الإجراءات وبناء شبكة من الإتصالات التي تؤمن توافر المعلومات الإهاء المطلوبة

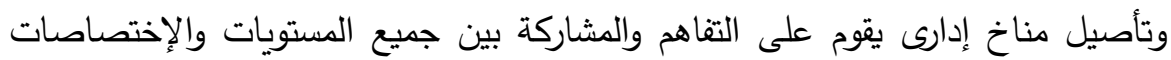

- Christine M. K. B. De. Greene, 1982) الوظيفية داخل وخارج المنظمة وتاصيل

.(Pearson and Judith A. Clair, 1998 ه-تعيين مسؤل إعلامي من فريق إدارة الطواريء يتولى الإتصال بوسائل الإعلام المختلفة،

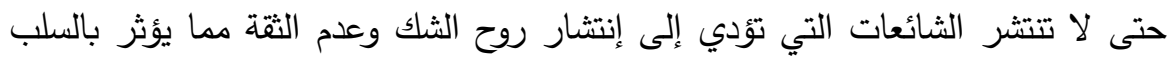
على العلاقات الداخلية بين العاملين، وبين المنشآت النووية والجمهور ( Laurance (Barton, 1991 وغيرها من الإثتراطات البناء خطة طوارىء متكاملة وفعالة .

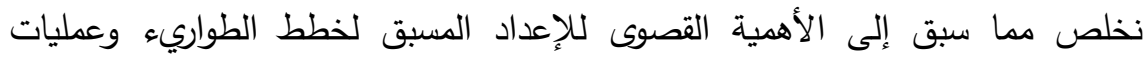
الإستجابة في حالات الحوادث الإثعاعية والتمرين عليها بما يحاكي الحادثة حتى تصبح كفيلة لصد أي أضرار ممكنة أو حتى تقليلها، لذا يجب دعم التتاغم بين فريق إعداد الخطط والأجهزة المعنية بوضعها على الصعيد البيئي والصحي والقانونى لفحص المعايير اللازمة لإدخال التدابير الوقائية في ضوء التقدم التكنولوجى للوصول إلى أسمى النتائج في الضمان والتأمين

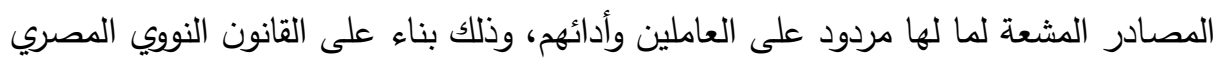

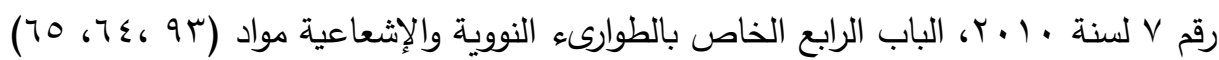
والمادة (1 • (1) من الباب السابع الخاص بالعقوبات .

\section{التراسمة الميدانية}

تتاول الباحثون منهجية البحث تفصيلاً للأسس المنهجية التي استنتجها في إعداد البحث، ويشمل ذلك تحديد نوع ومصادر البيانات، وتحديد مجتمع وعينة البحث، وأسلوب جمع البيانات، وأساليب التحليل الإحصائي للبيانات، وسوف يتم الاعتماد على المنهج الوصفي

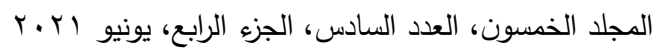

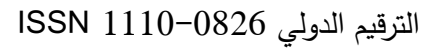


التحليلي، لوصف الظاهرة موضوع البحث وتحليل بياناتها وبيان العلاقة بين مكوناتها،

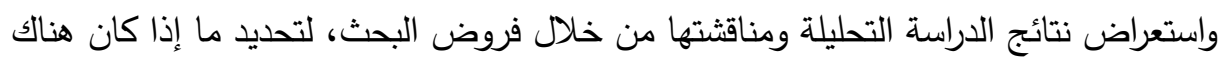

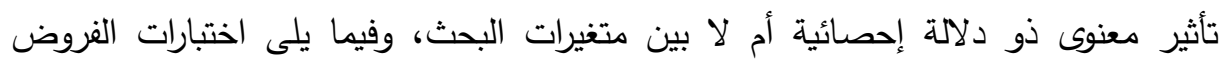
الخاصة بالبحث الحالي.

أولاً: منهج البحث وإجراء اته : بالئ

1 - منهج البحث: تم الاعتماد على المنهج الوصفي التحليلي، لوصف الظاهرة موضوع

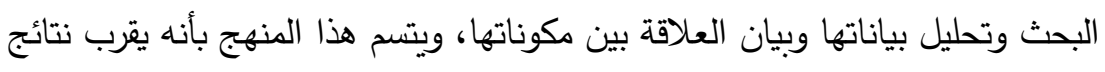
البحث من الواقع ويمكنها من وصف الظواهر بثكل دقيق.

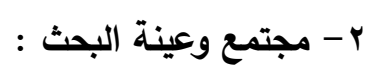

أ- مجتمع البحث: قام الباحثون بعمل الاستبيان فى هيئة الرقابة النووية والإشعاعية، وذلك لتحقيق أكبر نسب للمشاركة من كل الفئات العمرية والاجتماعية والمهنية والعلمية المختلفة.

ب- عينة البحث: حيث أن مجتمع البحث مجتمع كبير، قام الباحثون باستخدام العينة

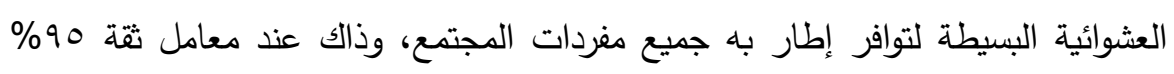

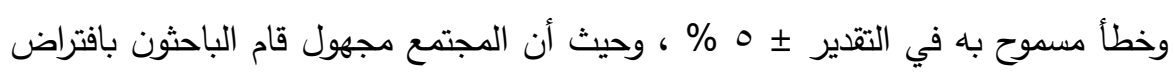

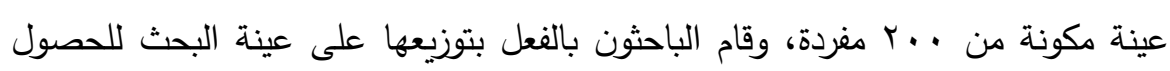

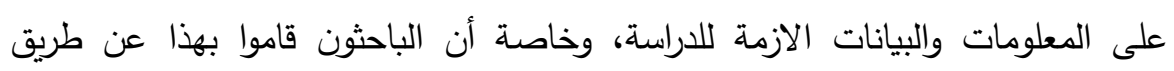
المقابلات الثخصية . مانى

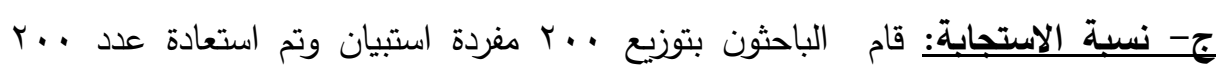

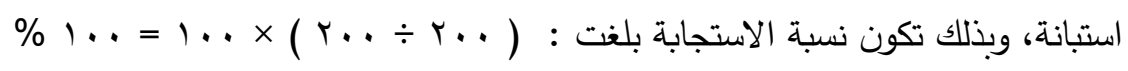

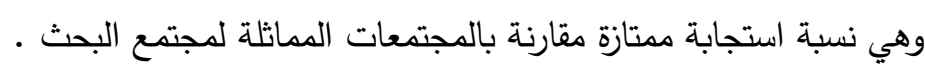

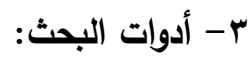




\section{مجلة العلوم البيئية \\ معهد الدراسات والبحوث البيئية - جامعة عين شمس للئس \\ أروى حسين محمد صلاح مكاوى وآخرون}

أ- مقايس البحث :ويعتمد البحث الحالية على استبيان مكون من قسمين الأول البيانات

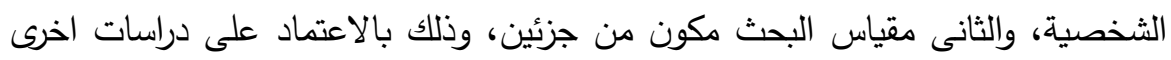
على النحو التالى :

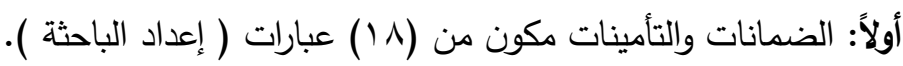

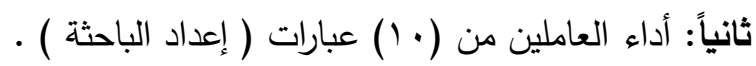

وبعد الانتهاء من جمع البيانات قام الباحثون بعمل تحليل لها بإستخدام على برنامج

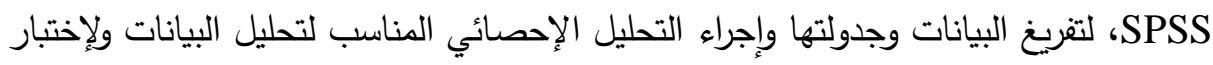
صحة فروض البحث، وتطلب ذلك تطبيق بعض أساليب الإحصاء الوصفي والإحصاء

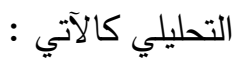

ب- قائمة الاستقصاء:تم تصميم استمارة استقصاء والتي تضمنت مجموعة من العبارات لقياس اتجاهات أفراد عينة البحث تجاه متغيرات البحث المختلفة، ولتصميم هذه الاستمارة قام الباحثون بالإطلاع على العديد من الدراسات السابقة في مجال موضوع البحث، وقد

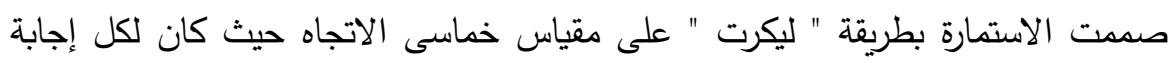
وزن، تم حساب معاملي الصدق (ألفا كرونباخ) والثبات لأسئلة الاستبيان في عينة البحث، لاتهاه

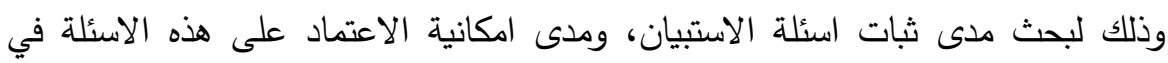

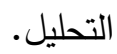

والجدول التإلى يوضح قيم معاملي الصدق والثبات لمحاور الاستبيان. جدول (1): معاملات الصدق والثبات

\begin{tabular}{|c|c|c|c|c|}
\hline معامل الثبات & معامل الصدق ألفاكرونباخ & عدد العبارات & المقياس & م \\
\hline., 900 & $\cdot, 9 \leq \pi$ & 11 & الضمانات والتأمينات & 1 \\
\hline$\cdot, 94$. & $\cdot, \wedge 77$ & 1. & أداء العاملين & $r$ \\
\hline
\end{tabular}

من الجدول السابق يتضح أن معاملات الصدق والثبات مقبولة لأسئلة الاستبيان ككل ,

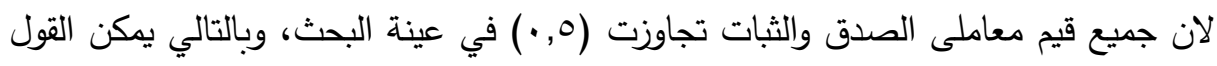

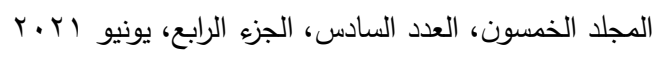

$$
\begin{aligned}
& \text { الترقيم الدولي 0826-0SN 1110 }
\end{aligned}
$$


أنها معاملات ذات دلالة جيدة لأغراض البحث، وبالتالي يمكن الاعتماد عليها في التحليل مع

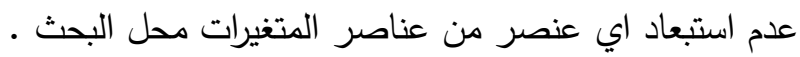

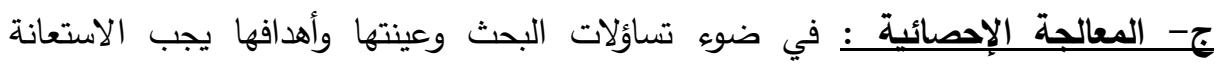
بالأساليب الإحصائية التالية: ا ـ معامل ألفا كرونباخ لحساب ثبات الأدوات المستخدمة في البحث. r. المتوسط الحسابي والانحراف المعياري. ז. معامل ارتباط بيرسون.

بعد الانتهاء من جمع البيانات قامت الباحثة بعمل تحليل لها بإستخدام على برنامج Statistical Package For Social Science) ،SPS الاجتماعية، لتفريغ البيانات وجدولتها وإجراء التحليل الإحصائي المناسب لتحليل البيانات ولإختبار صحة فروض البحث، وتطلب ذلك تطبيق بعض أساليب الإحصاء الوصفي والإحصاء التحليلي كالآتي:

أ) الإحصاء الوصفي: تم الاعتماد على الإحصاء الوصفي وكل من الوسط الحسابي

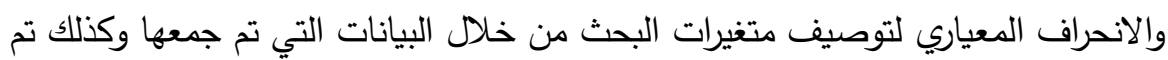
الاعتماد على معامل الفا كرو نباخ (Cronbach's Alpha) والذي يستخدم لقياس مدى لون الصدق والثبات للأسئلة الموجودة في الاستقصاء، وكذلك التأكد من مدى أهمية هذه الأسئلة بالإضافة إلى استخدام معامل إرتباط بيرسون وذلك لقياس ثبات أداة البحث. ب) الإحصاء الاستدلالي : اعتمد الباحث على تحليل بيانات البحث على أساليب الإحصاء التحليلي للتحقق من مدى صحة الفروض وهذه الأساليب كما يلي : تحليل الانحـدار الخطي البسـيط: هو اسلوب احصـئي يستخدم لاختبار أثر متغير

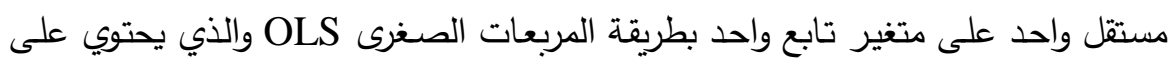
اختبار معاملات الانحدار (t)، واختبار النموذج الكلي (F) وبعض واحضع اختبارات التحقق من افتراضات المربعات الصغرى ماتمات الصنات 420

$$
\begin{gathered}
\text { المجلد الخمسون، العدد السادس، الجزء الرابع، يونيو الترقيم الدولي 0826-0 } \\
\text { ISSN 1110 }
\end{gathered}
$$




\section{مجلة العلوم البيئية \\ معهد الدراسات والبحوث البيئية - جامعة عين شمس للئه \\ أروى حسين محمد صلاح مكاوى وآخرون}

تحليل الانحدار الخطي المتعدد : هو اسلوب احصائي يستخدم لاختبار أثر اكثر من

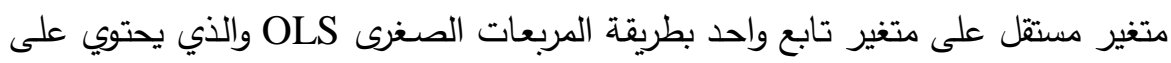
اختبار معاملات الانحدار (t)، واختبار النموذج الكلي (F) وبعض واحضير اختبارات التحقق من اقتراضات المربعات الصغرى.

\section{؛ - التحليل الاحصائي لنتائج البحث الميدانية :}

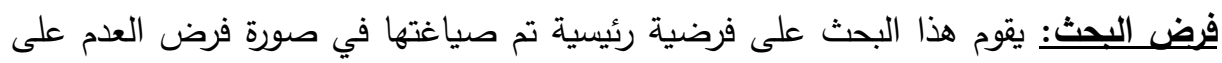

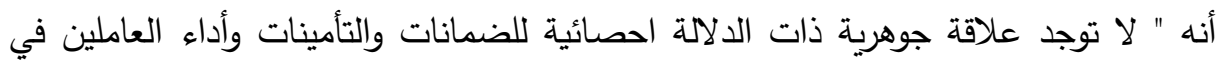

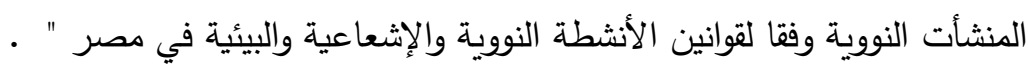
وحتى يتمكن الباحثون من اختبار الفرض قاموا باستخدام تحليل الاتحدار الخطي المتعدد Multiple Linear Regression Analysis

نتائج التحليل الإحصائي للفرض على ما يلي:

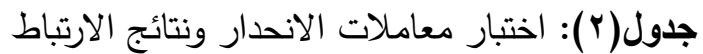

\begin{tabular}{|c|c|c|c|c|c|}
\hline بيرسون r الإجمالي & $\begin{array}{l}\text { القرار ع=0.05 } \\
\alpha=0.05\end{array}$ & مستوى الالالة & قيمة t & الانحدار & المتغير المستقل \\
\hline \multirow{2}{*}{ סזד, } & معنوي & $\cdot, \cdot$ & $1 \Gamma, \wedge$ & 1,90 & الحد الثابت \\
\hline & تأثير معنوي & $\cdot, \cdot$ & $V, q \leq$ & $\cdot, \Gamma_{0}$ & الضمانات والتأمينات \\
\hline
\end{tabular}

جدول(r): تحليل التباين ANOVA

\begin{tabular}{|c|c|c|c|c|}
\hline معامل التحديد r2 & القرار عند 0.05=0. & مستوى & قيمة F & المتغير التابع \\
\hline$\% \pi r, Y$ & معنوي & $\cdot, \cdot$ & $7 r, \cdot T$ & أداء العاملين \\
\hline
\end{tabular}

ا-بالنظر لجدول اختبار معامل ارتباط بيرسون وكذلك معامل الانحدار يتضح أن قيمة مستوى الدلالة اقل من قيمة مستوى المعنوية 0.05 م وهذا يعنى وجود علاقة معنوية ذات دلالة إحصائية بين الضمانات والتأمينات وأداء العاملين.

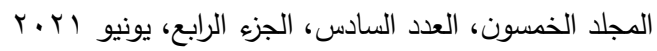

$$
\begin{aligned}
& \text { الترقيم الدولي 0826-08N 1110 }
\end{aligned}
$$


r-كانت إشارة معامل الانحدار الواردة في النموذج المقدر إثارة موجبة وهذا يعني وجود

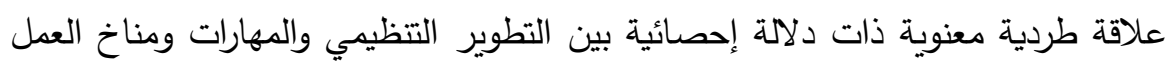
والإدارة بالمشاركة.

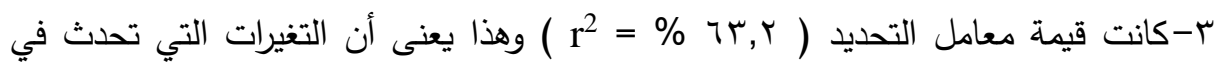

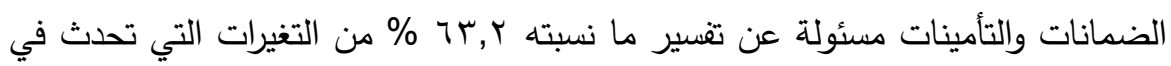
أداء العاملين والنسبة الباقية ترجع لوجود عوامل أخرى بالإضافة إلى حد الخطأ العشوائي .

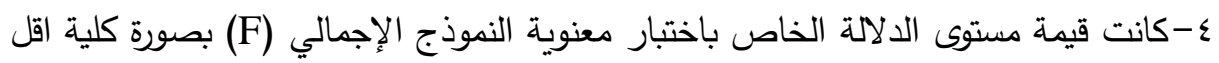

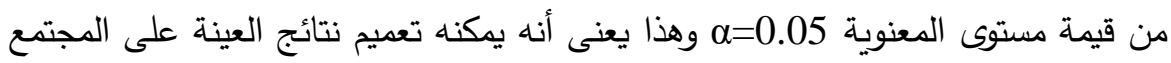
محل البحث.

مما سبق يمكن للباحث رفض الفرض في الصورة العدمية وقبول الفرض في الصورة البديلة التي تتص علي أنه " توجد علاقة جوهرية ذات الدلالة احصائية للضمانات والتأمينات

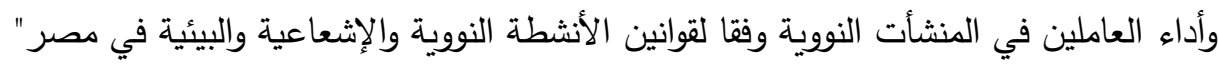

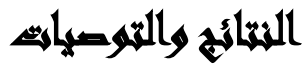

فيما يلى سوف يتم استعراض النتائج التى توصلت إليها البحث وأهم التوصيات .

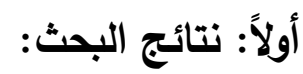

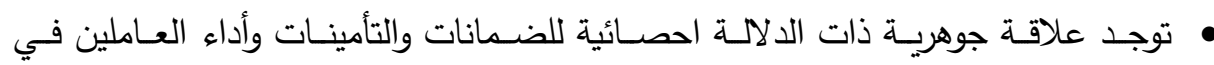

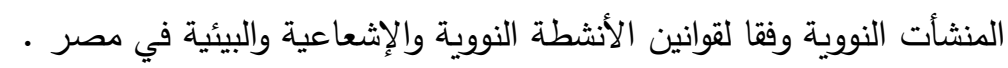

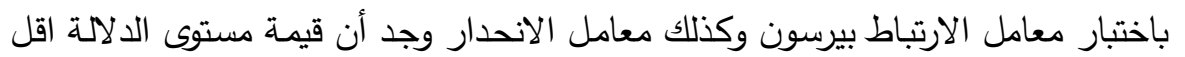
من قيمة مستوى المعنويـة 0.05 مهذ وهذا يعنى وجود علاقة معنويـة ذات دلالمة إحصائية بين الضمانات والتأمينات وأداء العاملين.

$$
\begin{gathered}
\text { المجلد الخمسون، العدد السادس، الجزء الرابع، يونيو ISSN 1110-0826 الترقيم الدولي } \\
\text { ISSN }
\end{gathered}
$$




$$
\begin{aligned}
& \text { مجلة العلوم البيئية } \\
& \text { معهد الدراسات والبحوث البيئية - جامعة عين شمس لئية } \\
& \text { أروى حسين محمد صلاح مكاوى وآخرون }
\end{aligned}
$$

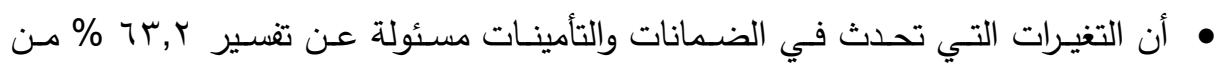

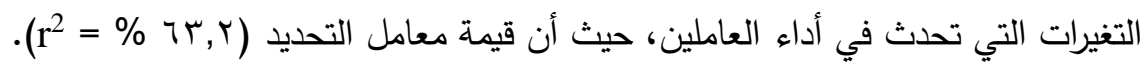

• أن الهيئات النوويـة أخذت بنظـام الخطط المعده مسبقأ لـنـع حدوث كوارث وكيفيـة إدارة

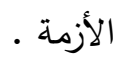

• إقتصر النظام القانوني الاستثنائي للمسؤولية المدنية عن الأضرار النوويـة على الاكتفاء

$$
\text { بركني الضرر) و (العلاقة السببية التي تربط بين الحادث النووي و الضرر ) }
$$

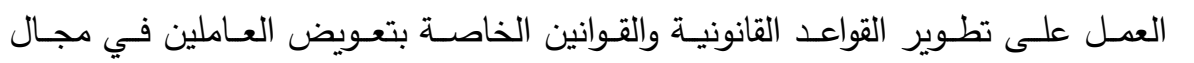

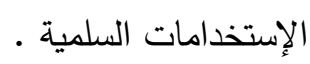

$$
\text { • أن القانون المدني هو الطريق لتعويض العمال المضرورين بالإشعاع. }
$$

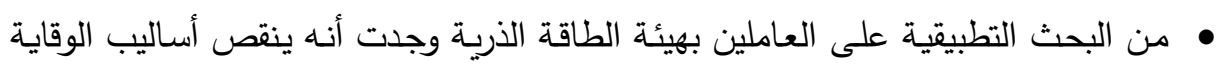

وحماية العاملين من الإشعاعات إلزام تطبيقها والجدية لإجراء الفحوصات الطبية الدورية

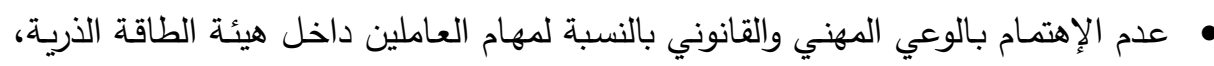

وضرورة تحديث القوانين بما يناسب الطبيعة الخاصة لأنشطة النووية .

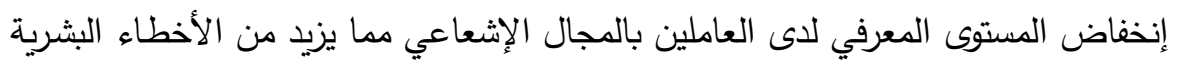

$$
\text { وحدوث حوادث . }
$$

• لم تتطرق البحث إلى الجانب القانوني والبحث عن عقوبات رادعة من ناحية، و العوامل

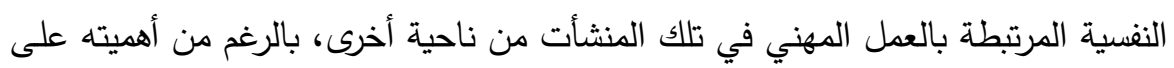

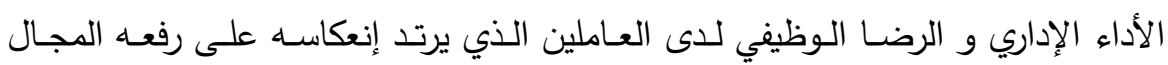

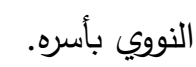

ثانياً: التوصيات:

• العمل على المزيد من التوعية بالادراك البيئي وعلاقته بعملهم وتأثثره في تقليل معدلات

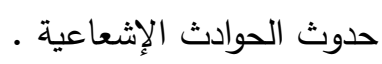

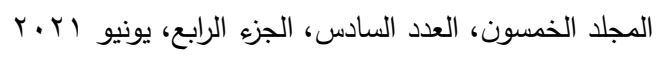

$$
\begin{aligned}
& \text { الترقيم الدولي 0826-0SN 1110 }
\end{aligned}
$$




$$
\begin{aligned}
& \text { مجلة العلوم البيئية } \\
& \text { معهد الدراسات والبحوث البيئية - جامعة عين شمس لئن آلمس } \\
& \text { أروى حسين محمد صلاح مكاوى وآخرون }
\end{aligned}
$$

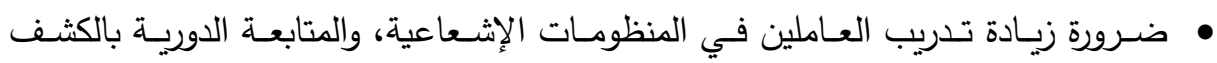

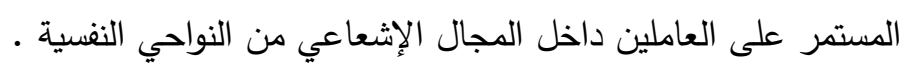

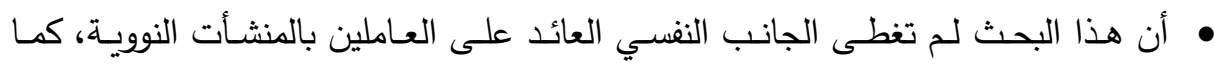

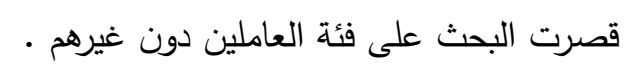

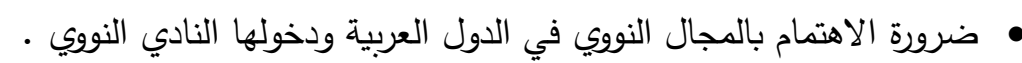
ه إلا أن هذه البحث أغلقت أبواب الاستبيان عن المواطنين العاديين و المصـابين بأضـرار

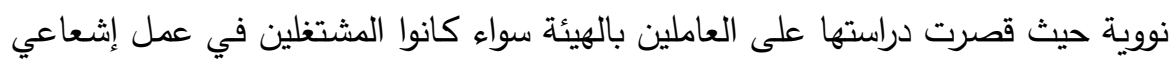
أو العاملين غير المشتغلين في عمل إثعاعى •

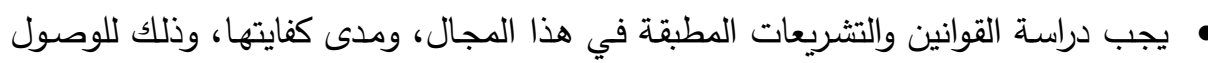

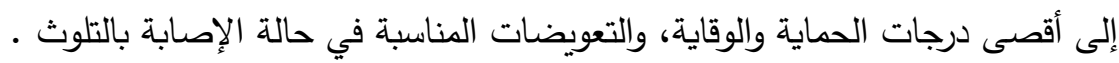

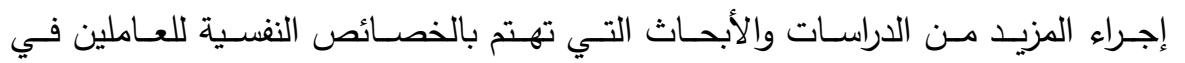
المنظومات الإشعاعية بغرض رفع كفاءة العاملين وزيادة أدائهم النفسي بما ينعكس على بلى تلى سير العمل في تلك المنظومات

\section{المراليع:}

أديب خضور (999 (1)): دور الإعلام في إدارة الأزمات، أكاديمية نايف العربية للعلوم الأمنية، الرياض.

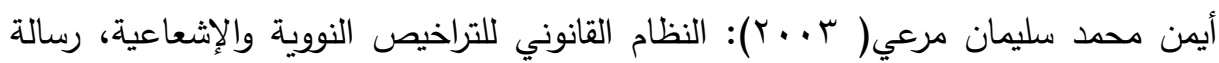
دكتوراة، جامعة القاهرة .

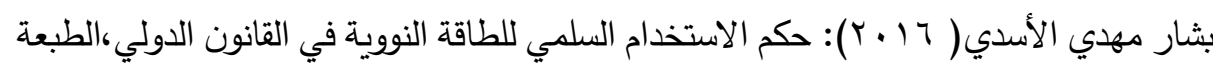

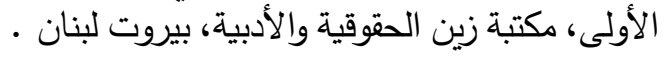

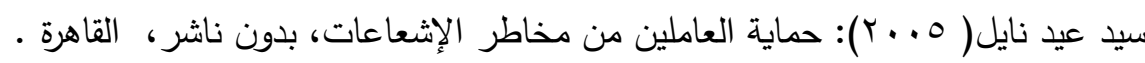

$$
\begin{gathered}
\text { المجلد الخمسون، العدد السادس، الجزء الرابع، يونيو ISSN 1110-0826 الترقيم الدولي } \\
\text { ISSN }
\end{gathered}
$$




$$
\begin{aligned}
& \text { مجلة العلوم البيئية }
\end{aligned}
$$

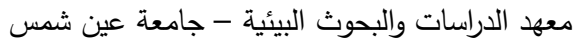

$$
\begin{aligned}
& \text { أروى حسين محمد صلاح مكاوى وآخرون }
\end{aligned}
$$

طارق زقلة، خطط الطواريء الإشعاعية من أجل عملية الإنسان والبيئة المحيطة، مجلة أخبار

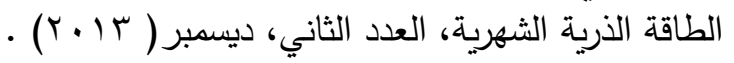

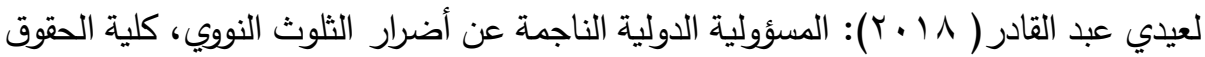
والعلوم السياسية، جامعة أبوبكر بلقايد تلمسان، وزارة التعليم العالي والبحث النئ النية

$$
\text { العلمي. }
$$

محمد ربيع فتح الباب(؟ ( • r): المسؤلية المدنية عن اضرار التلوث الإثعاعي النووي، دار

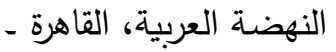

مروة حسين محمد صلاح( 1 ( ب ب): إطار مقترح لمعالجة مشكلات حقوق العاملين بالمنشآت

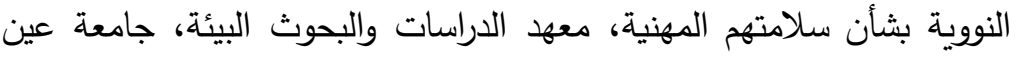

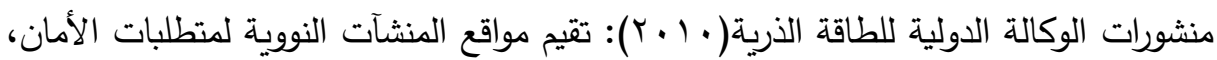

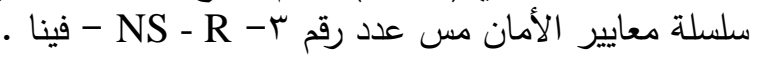

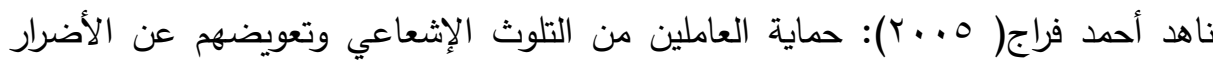

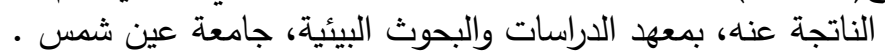

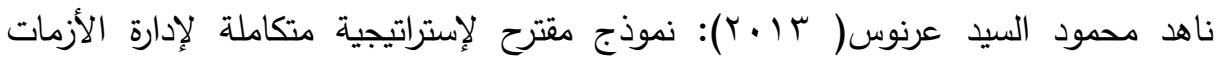

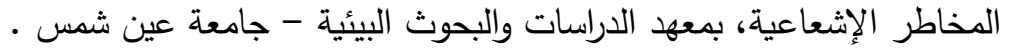

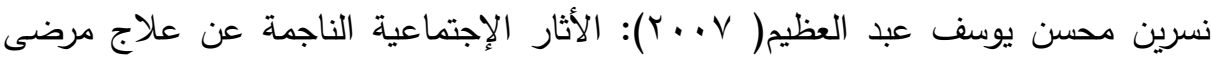
الأورام بالإشعاع، بمعهد الدراسات والبحوث البيد البينية، جامعة عين شمس.

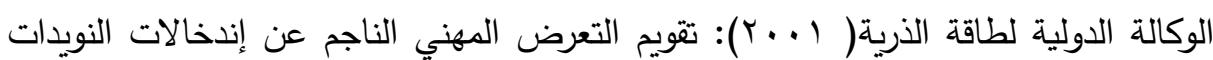

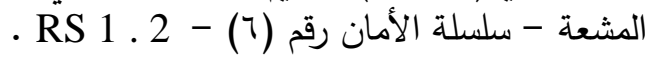

Chenu (CH.A) :Les dengers atomiqe et leur assurance, in A.D.E.A., ed C.N.R.s, 1. 1., paris, 1965.

Christine M. Pearson and Judith A. Clair, Reframing Crisis Management Academy of Management Review, Vol. 23 ,No. 1, January 1998 .

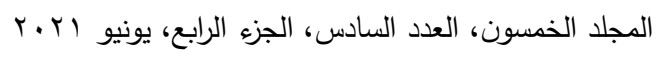

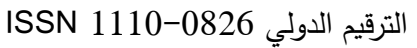




$$
\begin{aligned}
& \text { مجلة العلوم البيئية } \\
& \text { معهد الدراسات والبحوث البيئية - جامعة عين شمس } \\
& \text { أروى حسين محمد صلاح مكاوى وآخرون }
\end{aligned}
$$

International Atomic Energy Agency, Quality Assurance For Safety in Nuclear Power Plant and Other Nuclear Installa on: Code and Safety Guides Q1-Q14 - Safety Series No. 50-C/SG-Q, IAEA, Vienna, 1996.

K. B. De. Greene, the Adoptive Organization Anticepation and Management of Crisis, New York :John Wiley \& Sons, 1982.

Laurance Barton, Crisis Management Communication in the Heat of Chaos, Business Forum (LAB), Winter (1991).

\section{THE EFFECT OF SAFEGUARDS AND INSURANCES} ON THE PERFORMANCE OF WORKERS IN NUCLEAR FACILITIES IN ACCORDANCE WITH

\section{THE LAWS OF NUCLEAR, RADIOLOGICAL AND}

\section{ENVIRONMENTAL ACTIVITIES IN EGYPT}

Arwa H. M. S. Makawi (1); Faisal Z. Abd El Wahed(2);

Abd El-Raouf A. Gadallah ${ }^{(3)}$; Hussein M. Abdo ${ }^{(4)}$

1) Post graduate student at Institute of Environmental Studies \& Reesearch, Ain Shams University 2) Faculty of Law, Ain Shams University 3) Nuclear and Radiological Regulatory Authority 4) Faculty of Commerce, Ain Shams University

$$
\begin{gathered}
\text { المجلد الخمسون، العدد السادس، الجزء الرابع، يونيو ISSN 1110-0826 الترقيم الدولي } \\
\text { ISSN }
\end{gathered}
$$




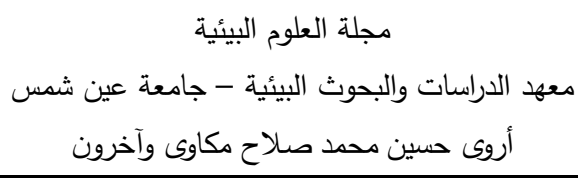

\begin{abstract}
This research seeks to achieve a main objective, which is to measure the impact of safeguards and insurances on workers in nuclear installations in accordance with the laws of nuclear activities, radiation and the environment in Egypt through achieving a set of sub-objectives, namely:

- Learn about the problems faced by workers in nuclear installations in Egypt .

- Determine what safeguards exist for workers in nuclear facilities in Egypt .

- Measuring the impact of safeguards and insurances on the performance of workers in nuclear facilities in Egypt .

- Reaching the best safeguards and insurances for workers in nuclear installations in Egypt, better if possible, and shedding light on the nature of the work of nuclear installations in Egypt .

- Educating workers and monitoring them to adhere to all means of radiation protection and keen to use them while setting the binding procedures to achieve this.

The descriptive analytical approach was relied upon to describe the phenomenon under study, analyze its data, and clarify the relationship between its components, through a questionnaire. (200) people.
\end{abstract}

The research found :

- There is a substantial, statistically significant relationship to guarantees, insurances, and the performance of workers in nuclear facilities in accordance with the laws of nuclear, radiological and environmental activities in Egypt .

- Nuclear agencies adopted a system of pre-prepared plans to prevent disasters and how to manage the crisis .

- Work to develop the legal rules and laws for the compensation of workers in the field of peaceful uses .

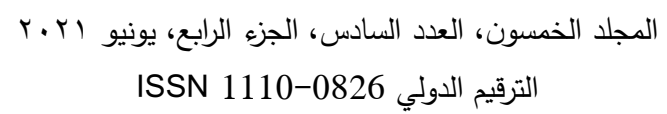




$$
\begin{aligned}
& \text { مجلة العلوم البيئية } \\
& \text { معهد الدراسات والبحوث البيئية - جامعة عين شمس لئس } \\
& \text { أروى حسين محمد صلاح مكاوى وآخرون }
\end{aligned}
$$

- Lack of attention to professional and legal awareness of the tasks of workers within the Atomic Energy Authority, and the need to update laws to suit the special nature of nuclear activities .

- A decrease in the level of knowledge of workers in the radiation field, which increases human errors and the occurrence of accidents .

Among the most important recommendations:

- Work on more awareness of environmental awareness and its relationship to their work and its impact on reducing the incidence of radiation accidents.

- The need to increase training of workers in radiological systems, and periodic follow-up by continuous examination of workers within the radiological field from psychological aspects.

- The necessity of paying attention to the nuclear field in the Arab countries and their entry into the nuclear club.

key words: Safeguards and assurances - Personnel performance Nuclear installations - Nuclear, radiological and environmental activities

$$
\begin{gathered}
\text { المجلد الخمسون، العدد السادس، الجزء الرابع، يونيو ISSN 1110-0826 الترقيم الدولي } \\
\text { ISSN }
\end{gathered}
$$

